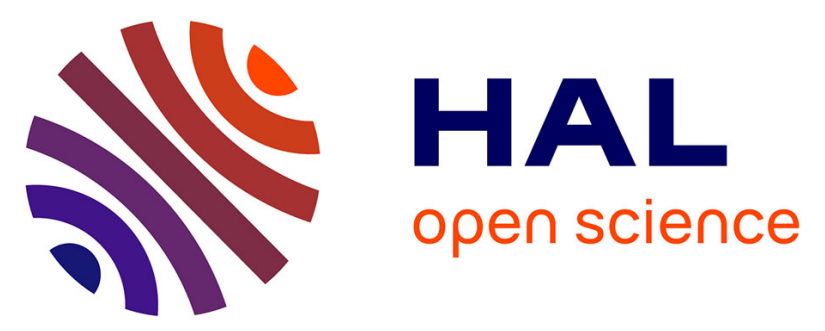

\title{
Electron Storage System Based on a Two-Way Inversion of Redox Potentials
}

Alexis Gosset, Liam Wilbraham, Štěpánka Nováková Lachmanová, Romana

Sokolová, Grégory Dupeyre, Fabien Tuyèras, Philippe Ochsenbein, Christian

Perruchot, Henri-Pierre Jacquot de Rouville, Hyacinthe Randriamahazaka, et al.

\section{To cite this version:}

Alexis Gosset, Liam Wilbraham, Štěpánka Nováková Lachmanová, Romana Sokolová, Grégory Dupeyre, et al.. Electron Storage System Based on a Two-Way Inversion of Redox Potentials. Journal of the American Chemical Society, 2020, 142 (11), pp.5162-5176. 10.1021/jacs.9b12762 . hal03084130

\section{HAL Id: hal-03084130 https://hal.science/hal-03084130}

Submitted on 20 Dec 2020

HAL is a multi-disciplinary open access archive for the deposit and dissemination of scientific research documents, whether they are published or not. The documents may come from teaching and research institutions in France or abroad, or from public or private research centers.
L'archive ouverte pluridisciplinaire $\mathbf{H A L}$, est destinée au dépôt et à la diffusion de documents scientifiques de niveau recherche, publiés ou non, émanant des établissements d'enseignement et de recherche français ou étrangers, des laboratoires publics ou privés. 


\section{Electron Storage System Based on a Two-Way Inversion of Redox Potentials}

Alexis Gosset, ${ }^{\mathrm{a}}$ Liam Wilbraham, ${ }^{\mathrm{b}}$ Štěpánka Nováková Lachmanová, ${ }^{\mathrm{c}}$ Romana Sokolová, ${ }^{\mathrm{c}}$ Grégory Dupeyre, ${ }^{\mathrm{a}}$ Fabien Tuyèras, ${ }^{\mathrm{a}}$ Philippe Ochsenbein, ${ }^{\mathrm{d}}$ Christian Perruchot, ${ }^{\mathrm{a}}$ HenriPierre Jacquot de Rouville, ${ }^{\text {a,f }}$ Hyacinthe Randriamahazaka, ${ }^{*, a}$ Lubomír Pospíšil, ${ }^{*, c, e}$ Ilaria Ciofini, ${ }^{*, b}$ Magdaléna Hromadová,*,c Philippe P. Lainé*,a

a Université de Paris, ITODYS, CNRS, UMR 7086, 15 rue J-A de Baïf, F-75013 Paris, France

${ }^{\mathrm{b}}$ Chimie ParisTech, PSL University, CNRS, Institute of Chemistry for Life and Health Sciences, Theoretical Chemistry and Modelling, 11 rue Pierre et Marie Curie, 75005 Paris, France

c J. Heyrovský Institute of Physical Chemistry of the Czech Academy of Sciences, Dolejškova 3, 18223 Prague, Czech Republic

d Laboratoire de Cristallographie et Modélisation Moléculaire du Solide, Sanofi LGCR, 371 rue du Professeur Blayac, 34184 Montpellier Cedex 04, France

e Institute of Organic Chemistry and Biochemistry of ASCR, v.v.i., Flemingovo n.2, 16610 Prague, Czech Republic

${ }^{\mathrm{f}}$ Present address: Université de Strasbourg, Institut de Chimie de Strasbourg (UMR CNRS 7177), Institut Le Bel, 4, rue Blaise Pascal, 67000 Strasbourg-France

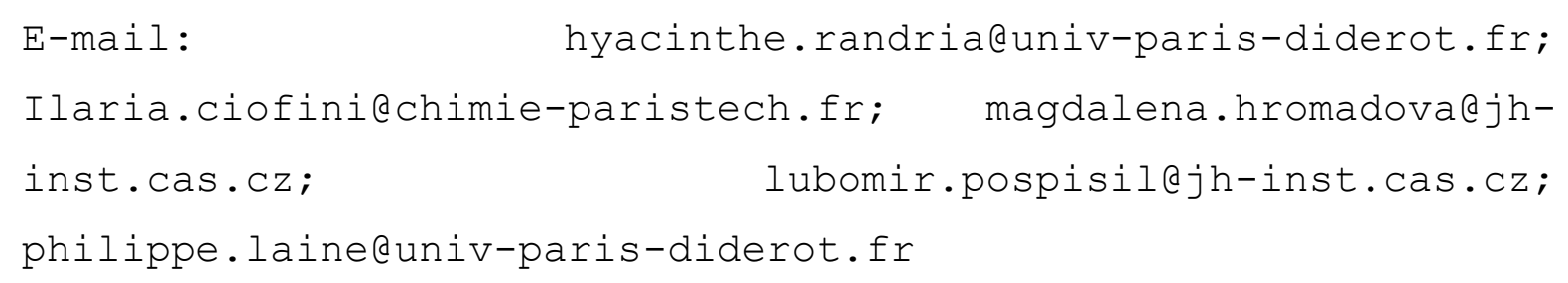




\section{Abstract.}

Molecular-level multielectron handling towards electrical storage, is a worthwhile approach to solar energy harvesting. Here, a strategy which uses chemical bonds as electron reservoirs is introduced to demonstrate the new concept of "structronics" (a neologism derived from "structure" and "electronics"). Through this concept, we establish, synthesize, and thoroughly study two multicomponent "superelectrophores": 1,8-dipyridyliumnaphthalene, 2, and its $N, N^{-}$ bridged cyclophane-like analogue, 3. Within both of them, a covalent bond can be formed and subsequently broken electrochemically. These super-electrophores are based on two electrophoric (pyridinium) units that are, on purpose, spatially arranged by a naphthalene scaffold. A key characteristic of $\mathbf{2}$ and $\mathbf{3}$ is that they possess a LUMO that develops through space as the result of the interaction between the closely-positioned electrophoric units. In the context of electron storage, this "super-LUMo" serves as an empty reservoir, which can be filled by a two-electron reduction, giving rise to an elongated $\mathrm{C}-\mathrm{C}$ bond or "superHOMO". Because of its weakened nature, this bond can undergo an electrochemically driven cleavage at a significantly more anodic - yet accessible - potential, thereby restoring the availability of the electron pair (reservoir emptying). In the representative case study of $\mathbf{2}$, an inversion of potential in both of the two-electron processes of bond formation and bond-cleavage is demonstrated. Overall, the structronic function is characterized by an electrochemical hysteresis and a chemical reversibility. This structronic superelectrophore can be viewed as the three-dimensional counterpart of benchmark methyl viologen. 


\section{Introduction}

In the context of global warming ${ }^{1,2}$ the sun is now recognized as a relevant alternative to fossil fuels.3,4 Multifarious technological and societal changes are deemed to accompany this advent to make possible the desirable change of primary energy source in optimal conditions.5,6 As is the case in natural photosynthesis, its artificial counterpart ${ }^{7}$ as well as man-made devices meant to solar energy transduction (e.g. photovoltaics, DSSCS) ${ }^{8}$ largely rely on electrons for their functioning. Likewise, both the handling of multielectron/hole accumulation and the storage of electricity is performed using chemical energy, whether these processes occur within nature or within artificial setups such as batteries and fuel cells.

Here we tackle the fundamental issue of the extent to which a working principle for the storage of electrons can be established at the molecular level, combining chemical reversibility (represented by cyclability in secondary electric batteries) with the thermodynamic irreversibility of the bond formation and cleavage processes of fuel cells. To do so, we assess the possibility of using electrochemistry, exploiting non-catalyzed processes of formation and cleavage of a single chemical bond. This bond is conceived for its dual ability of being formed upon attaching electrons as the only reagents, that is upon reduction, and to yield electrons upon breaking it that is, upon oxidation (in analogy to the charging and discharging of secondary batteries). We refer to this concept as structronics (from "structural" and "electronics"), which is characterized by "using a chemical bond as a reservoir for electron storage". As this concept concerns the ability to go back and forth between binary states (chemical reversibility combined with thermodynamic irreversibility), it is closely related to the notion of electrochemical hysteresis (see Scheme SI in SI) and proceeds 
according to a two-way inversion of redox potentials. Thereby storage is distinguished from the mere process of charges (electrons) accumulation, $4 \mathrm{c}, \mathrm{d}$ which rather refers to thermodynamically reversible processes, or alike.9,10

Fundamentally, this concept represents a core functionality and, as such, with the exchanged electrons as energy vectors may serve as a means for energy storage. Indeed, in the context of solar energy conversion, given that light absorption is a one-photon process that results in a one-electron charge-separation process, ${ }^{4 c}$ at least two of those photons are formally "consumed" per structronic functional species for its charging i.e. C-C bond formation, hence the relevance of using such a bond for photoelectrochemical energy storage (two-photon/two-electron gated reversible Carbon-Carbon bond). ${ }^{11}$ Last, thanks to hysteretic behavior of the structronic elements, these can serve as a means for the molecular-level storage of information (molecular electronics). ${ }^{12}$

\section{Molecular design}

For molecular-level charge confinement, the adverse effect to be overcome is the ubiquitous electrostatic repulsion of like charges for both charge accumulation and storage. Detailed explanation of these two terms in connection with the herein reported molecular design of charge reservoirs, is given in section 53 of the SI.

The redox-active units of reservoirs are initially defined in their closed-shell native redox state, represented by their initial charge [z]. This notation extends to their reactive (i.e. open-shell) radical states, which may be obtained following a one-electron reduction $[z-1]$ or a oneelectron oxidation $[z+1]$ process. Similarly, species obtained after a two-electron reduction are denoted as [z 2]. Based on energetics, cationic units are preferred as 
electrophoric components for electrons whereas neutral or anionic units are preferred for holes. In both cases, the design strategy consists of assembling electrophoric subsystems so as to formally generate closely lying radicals upon reduction or oxidation, thereby formally preparing them for the formation of the reservoir bond (Chart 1). The scope of the present work is restricted to the simplest case of a prototypical covalent assembly based on monocationic electrophoric components $(z=1+)$ that are involved in the reductive formation (and the oxidative cleavage) of a twoelectron bond, which functions as a two-electron reservoir.

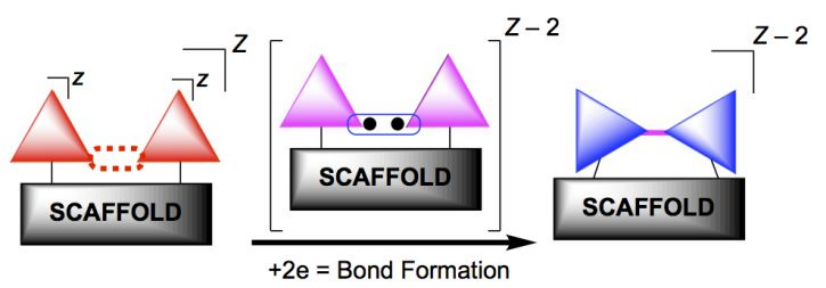

Chart 1. Generic representation of the molecular design strategy of the three-dimensional super-electrophore assembly ("structronics" function), which is disconnected from any mechanistic considerations. Electrophoric units (triangles) are pre-organized by the scaffold (spatial layout and strain tuning). The charge of cationic super-electrophore here amounts to $[z]=[z]+[z]=2+$ in its native redox state.

At this stage, the question is raised as to whether 2electron/2-center or 2-electron/n-center (i.e. "pancake")13 covalent bonds are the most suitable to function as electron reservoirs. The selection of the former is primarily dictated by the feasibility of a mechanical cleavage of the bond ondemand, that is, the a priori possibility of restoring the availability of the electrons (discharging process) using an electro-chemo-mechanical effect or the coupling with a stimulus-responsive molecular actuator. It remains nonetheless that this selection will have to be validated. Above-mentioned critical feature requires that this reservoir bond is conveniently weakened i.e., properly elongated. It follows that the choice of the scaffold responsible for (pre) assembling (and constraining) the electrophoric units is 
crucial. In addition to setting-up a precise spatial layout of the redox-active components, it ensures the adequate straining, and therefore weakening, of the interelectrophoric reservoir bond, once formed (Chart 1). Brought together, the electrophoric units and the assembling unit (scaffold) are the basic functional elements that allow the implementation of structronic function, that is, hysteretic electrochemical behavior for storage, giving rise to the specific covalent architecture referred to as a superelectrophore (in this context, a bistable system). Even though the process of bond formation/cleavage is expected to be chemically reversible, the molecular-level function relies on thermodynamic irreversibility that, here, takes the form of bistability, with different electrochemical pathways for bond formation and bond cleavage.

The whole aim of this proof of concept paper is to engineer the inter-component (through-space) orbital overlap to yield a LUMO which functions as a "two-electron trap". Therefore, one must switch the point of reductive reactivity from the individual electrophoric components to the superelectrophoric assembly as a whole.

Based on the above-defined criteria, we consider the pyridinium moiety as electrophoric component (Chart 2). This choice was made firstly because of the intrinsically uneven distribution of atomic contributions to the LUMO over its heteroaromatic ring, characterized by the large involvement of the carbon atom at the $\gamma$ position $(\mathrm{C}(\gamma) \text {; Chart } 2 \mathrm{a})^{14}$ and secondly, for its ability to rather easily overcome aromaticity to adopt a post-reduction quinoidal structure. ${ }^{15}$ Furthermore, pyridinium derivatives are remarkably versatile, especially regarding their redox properties, which can be tuned over a range of potentials of c.a. $1.5 \mathrm{~V} .{ }^{16}$ As the scaffold, we selected the naphthalene platform (with 1,8connectivity) that has the great asset of being structurally 
flexible enough through skeletal distortion, ${ }^{17,18}$ which is of interest for adjusting the strain on the reservoir bond (whether via cross clamping, front strain or remote (back) strain; Chart 2C). ${ }^{19}$

(a)
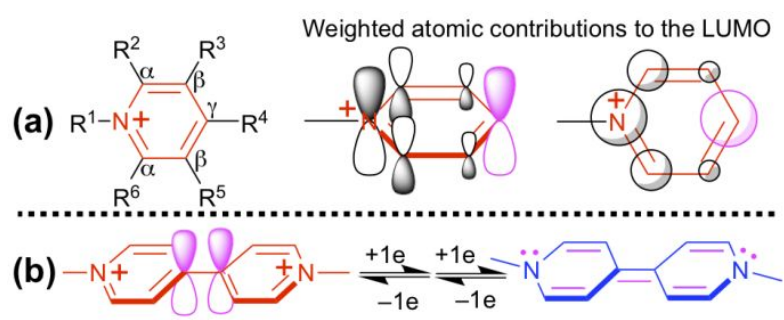

$\pi$-Type Overlap

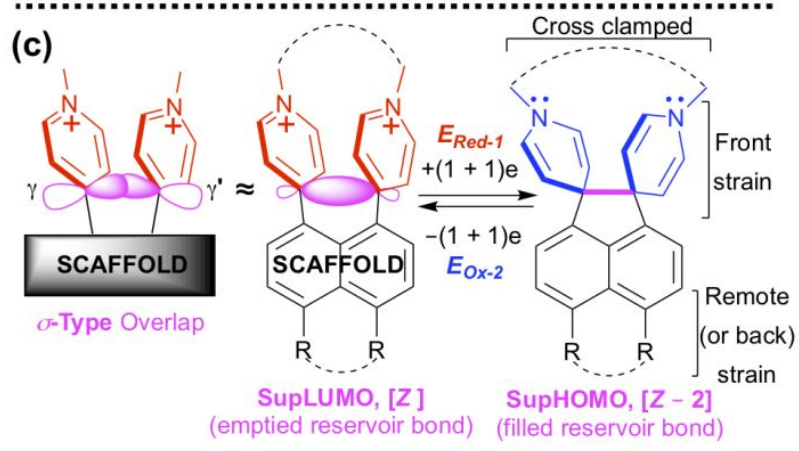

Chart 2. Molecular design of "structronic" prototypes: organizing electro-structural synergy. (a) Pictorial representation of the weighted atomic contributions ( $p_{z}$ atomic orbitals, AOs) to the LUMO of a pyridinium ring with emphasis on the large contribution of the $C(\gamma)$ position. (b) Representation of the in-plane pi-overlap between $\mathrm{p}_{z}$ AOs of the two $C(\gamma)$ atoms of native $\mathbf{M v}^{2+}$, which form the basis of the second interannular bond involved in the overall quinoidal electronic structure adopted by $\mathbf{M V}^{0}$ (following the stepwise two-electron reduction of $\mathbf{M V}^{2+}$ ). (c) Representation of the sigma-type, out-of-plane, overlap of $p_{z}$ AOs of the $C(\gamma)$ atoms within the three-dimensional super-electrophore (i.e. SupLUMO build-up) in the structronic context, leading to the formation of the elongated $\mathrm{C}_{\mathrm{sp} 3}-\mathrm{C}_{\mathrm{sp} 3}$ reservoir bond following an apparent single-step two-electron transfer ( SupHOMO) .

Connected at positions 1- and 8- of naphthalene (Chart 2), the two pyridinium units within the super-electrophore are anticipated to have their $C(\gamma)$ carbon atoms in close vicinity, lying at a distance $\left(d\left(C(\gamma)-C\left(\gamma^{\prime}\right)\right)\right.$ smaller ${ }^{20}$ than the sum of their van der Waals (vdW) radii $(1.70 \times 2=3.40$ $\AA) .{ }^{21}$ This critical short contact serves to maximize orbital interaction (overlap) between the two rings at precisely the $C(\gamma)$ sites where the LUMO of each pyridinium component has a large contribution (Chart $2 \mathrm{a} \& 2 \mathrm{c}$ ). In other words, instead 
of the in-plane $\Pi$-type delocalization that typically takes place within the archetypal reference molecule $\mathbf{M V}^{\mathbf{2}}$ (Chart 2b), an out-of-plane sigma-type overlap of the LUMOs of the two pyridinium building blocks is targeted as a result of their three-dimensional pre-organization (Chart 2c). ${ }^{22}$ This new bonding, virtual "supramolecular"23 orbital generated within the covalent assembly is in fact the LUMO of the whole dicationic super-electrophore and its key feature. This orbital that translates the electro-structural synergy is herein referred to as the SupLUMO. This SupLUMO of the native $([Z]=2+)$ super-electrophore is to be filled upon twoelectron reduction thus leading to the desired electronreservoir bond, which incidentally corresponds to the SupHOMO of the two-electron reduced $\left(\left[\begin{array}{ll}Z & -\end{array}\right]=0\right)$ superelectrophore. ${ }^{25}$

In order to assess the impact of the tailor-made supramolecular assembly (i.e. the inner askew stacking of electrophoric components) on pyridinium electrochemistry and to investigate the process of strained-bond formation (and breaking), we synthesized and studied, in parallel, the monopyridinium assembly $\mathbf{1}^{+}$and 4,4'-(naphthalene-1,8-diyl)bis(1methylpyridin-1-ium), $\mathbf{2}^{2+}$, the latter being a prototypical super-electrophore for electron storage (see Chart 3). For both $\mathbf{1}^{+}$and $\mathbf{2}^{2+}$, structural characterization in the solid-state (single-crystal $\mathrm{X}$-Ray diffraction) and in solution $\left({ }^{1} \mathrm{H}\right.$ and ${ }^{13} \mathrm{C}$ NMR) were carried out as well as the study of their electrochemical and in-situ spectroelectrochemical (SEC) properties, probing their electronic (UV-vis-NIR) and vibrational (FTIR) characteristics. Experimental findings were advantageously combined with molecular modeling using DFT and TD-DFT. Further, in order to unambiguously establish the number of electrons involved in the observed redox processes, the reference compound $\left(\mathbf{1}^{+}\right)$and the prototypical 
super-electrophore $\left(\mathbf{2}^{2+}\right)$ were both derivatized with ferrocenyl (FC) group (s) as single-electron redox probe (s) ( $\left.\mathrm{Fc}^{+} / \mathrm{Fc}\right)$, giving $\mathbf{1 F c ^ { + }}$ and $\mathbf{2} \mathbf{F c}^{2+}$, respectively (see Chart 3). Last, we also synthesized and studied the cyclophane-like analogue of $\mathbf{2}^{2+}$ referred to as $3^{2+}$ that is, $N, N^{\prime}-(n-$ butyl)-1,8-di (pyrid-4ylium)naphthalene, in order to assess the impact of an increase of front strain via cross clamping of the electrophoric components (Chart 2c and chart 3) on electrochemistry and especially the magnitude and positioning for the electrochemical hysteresis (see also section S25 and Figure S16 in SI). Beyond the frustration effect on electrostructural relaxation of the reduction product $\left(3^{0}\right)$, this last super-electrophore is also anticipated to providing us with the opportunity of getting some insights into the questioned relevance of using a 2-electron/multicenter pseudo-pancake covalent bonding as electron reservoir.

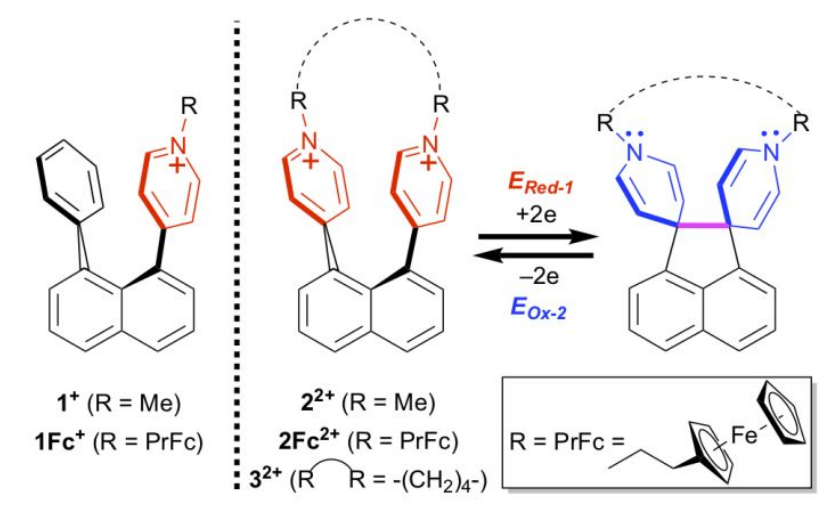

Chart 3. Molecular structures of the reference single-pyridinium electrophoric assembly, $\mathbf{1}^{+}$, and of the two-pyridinium super-electrophores, $\mathbf{2}^{2+}$ and $\mathbf{3}^{2+}$ (hosting the bond that functions as a two-electron reservoir) along with ferrocenyl derivatives $\mathbf{1 F c}^{+}$and $\mathbf{2} \mathbf{F} \mathbf{c}^{2+}$. Syntheses and full characterization of various compounds are reported in SI (Section S28).

\section{Results and discussion}

For consistency reasons, all studies in solution (whether experimental or theoretical) were performed with acetonitrile (MeCN) solvent, using an implicit solvent model for calculations (see Experimental Section). 
3.1. Synthetic strategy. For the purpose of the present study, besides the synthesis of the precursors of mono- and di-pyridylnaphthalene via Suzuki-Miyaura coupling (see Section S26 in SI), we have adopted a strategy that allows, in a single step, the pyridinium formation (quaternarization) or the Fc-derivatization via a saturated spacer that ensures the electronic decoupling of redox-active subunits (i.e. Fc and pyridinium). This approach, that relies on 3iodopropylferrocene $e^{26}$ as a key synthon, is potentially implementable with various kinds of compounds having pendant pyridyl groups, when it is desired, for instance, to attach redox probes to count the electrons involved in a redox process while avoiding diffusion effects, 14,16a,27 as is the case here.

3.2. Solid-State Characterization. The molecular structures of $\mathbf{1}\left[\mathrm{PF}_{6}\right], \quad \mathbf{2}\left[\mathrm{PF}_{6}\right]_{2}$ and $\mathbf{3}\left[\mathrm{PF}_{6}\right]_{2}$ were determined by single-crystal $X$-Ray diffraction (see Figure $S 1$ and Section $S 4$ in SI). Analysis of the solid-state structure of $2^{2+}$ confirms that the two pyridinium rings connected at positions 1- and 8- of the naphthalene scaffold are not stacked in a strictly parallel fashion but are askew arranged.

The fact that distortion of molecular backbones is observed in both $\mathbf{2}^{2+}$ and $\mathbf{1}^{+}$regardless of the charge they hold in their native form, indicates that steric hindrance rather than adverse electrostatic repulsion (case of $\mathbf{2}^{2+}$ ) primarily governs the overall structural features, as expected. This finding agrees with previous results derived from the study of congested polyacenes. ${ }^{17,28}$ Interestingly, and as expected, the bridging of electrophoric subunits in $3^{2+}$ via their $\mathrm{N}_{\text {pyridinio }}$ atoms is found to improve the cofacial layout of the pyridiniums (better pre-organization), enforcing the naphthalene scaffold to decreasing its distortion, as 
reflected by $\mathrm{ABCD}$ and $\theta$ angles, which amount to $2.78^{\circ}$, and $13.49^{\circ}$, respectively (see Figure S1 in SI).

A key parameter, especially for $\mathbf{2}^{2+}$ and $\mathbf{3}^{2+}$, is the $C(\gamma)-C\left(\gamma^{\prime}\right)$ distance (see Chart $2 \mathrm{C}$ and $d\left(C(\gamma)-C\left(\gamma^{\prime}\right)\right.$ ) in Figure S1). From single-crystal $\mathrm{x}$-ray crystallography of $\mathbf{2}$ in the native state (i.e. $\mathbf{2}^{2+}$ ), which contains two molecular assemblies per asymmetric unit, a single distance is found to be shorter than $3.4 \AA$, which is indeed $d\left(C(\gamma)-C\left(\gamma^{\prime}\right): 2.993 \AA / 3.012 \AA\right.$, as expected. On the contrary, three couples of atoms are found to be in close contact within $3^{2+}$, thereby satisfying the vdW criterion of a $3.4 \AA$ maximum separation distance: the $d\left(C(\gamma)-C\left(\gamma^{\prime}\right), 2.958 \AA\right.$, and the two $d\left(C(\beta)-C\left(\beta^{\prime}\right)\right.$ atom pairs: $3.146 \AA$ and $3.291 \AA$. It is thus anticipated that bonding interactions will be different in $\mathbf{2}^{0}$ and $\mathbf{3}^{0}$. Even if the above picture of inner structural features of super-electrophores 2 and 3 in their native state $([Z]=2+)$ are derived from solid-state characterization, one can reasonably expect that virtualy identical (although averaged) distortions are present in solution.

Overall, the combination of the steric front strain ${ }^{19}$ between pendant pyridylium groups with the intrinsic torsional flexibility of naphthalene scaffold,17 and the prominent contribution of the $\mathrm{C}(\gamma) \quad \mathrm{p}_{\mathrm{z}}$ orbitals to the LUMO, come together to favor a single through-space short contact within 2. On the contrary, with supplementary cross clamping i.e. within the cyclophane-like model 3, an enforced inner pseudostacking (characterized by the almost cofacial layout of heteroaromatic rings) is observed, which results in multiple short contacts that could lead to a 2-electron/n-center covalent bonding upon reduction (see below).

3.3. Molecular Modeling. DFT calculations were performed to gain further insight into the molecular geometries and 
electronic structures (frontier molecular orbitals) of the native and reduced forms of $\mathbf{1}, \mathbf{2}$ and 3 .

Geometry optimization of $\mathbf{1}, \mathbf{2}$ and $\mathbf{3}$ in their native forms, although obtained using a continuum representation of the solvent, accurately reproduces the salient geometrical features observed in the solid-state as determined from single-crystal $x$-ray crystallography. This finding is reflected in the good agreement of calculated values with experimental data for the above-defined geometrical parameters - $d\left(C(\gamma)-C\left(\gamma^{\prime}\right)\right), A B C D$ torsion angles, $\theta, \phi$ and $\tau$ (vide supra and Figure S1 and Table S1.1 in SI).

The calculated LUMO of model compound $\mathbf{1}^{+}$is essentially localized on the pyridinium subunit, with major contributions from the $\alpha$ and $\gamma$ positions (Figure 1 ). For both $\mathbf{2}^{2+}$ and $\mathbf{3}^{2+}$, the LUMO is localized on the ensemble made of the two interplaying pyridinium subunits, with major contributions from the $\mathrm{C}(\gamma) / \mathrm{C}\left(\gamma^{\prime}\right)$ atoms. Indeed, the close proximity of the two electrophoric components $\left(d\left(C(\gamma)-C\left(\gamma^{\prime}\right)\right)\right.$ calculated distance $=3.039 \AA$ and $2.983 \AA$ ) result in the through-space bonding interaction (sigma-type overlap) between the $p_{z}$ orbitals of the $C(\gamma)$ and $C\left(\gamma^{\prime}\right)$ atoms. From the standpoint of electronic structure, the lowest unoccupied "molecular" orbital of $\mathbf{2}^{2+}$ and $\mathbf{3}^{2+}$ characterizes this two-pyridinium ensemble as a unified assembly, ${ }^{23}$ which we may refer to as the necessary SupLUMO feature of the super-electrophore defined in section 2. Owing to the cross-conjugated nature of the unsaturated naphthalene scaffold with 1,8 -connectivity, ${ }^{29}$ it is most likely that the through-space supplementary bonding interaction in dipyridinium species directly explains the lower energy calculated for their SupLUMO $(E n .=-3.14 \mathrm{eV}$ and $-3.30 \mathrm{eV}$ for $\mathbf{2}^{2+}$ and $\mathbf{3}^{2+}$, respectively) as compared to the energy calculated for the LUMO of $1^{+}(E n .=-2.73 \mathrm{eV})$. 


(Energy / (Energy / (Energy I

Figure 1. Relevant molecular orbitals for single-, $\mathbf{1}$, and double- $\mathbf{2 / 3}$ pyridinium electrophores in native [Z], singly reduced [ $Z-1]$ and doubly reduced [ $z$ - 2] forms. These frontier MOs were calculated using the PBE0 exchange-correlation functional and are plotted with an iso-contour value of 0.04 . The corresponding orbital energies are also given in eV.

Concerning the reduced species, it appears that structural reorganization upon reduction/oxidation is neither of the 
same type nor of the same magnitude for $\mathbf{1}^{+}$(see SI, Section S8.2), $\mathbf{2}^{2+}$ and $\mathbf{3}^{2+}$ (Figure S2 in SI). For both $\mathbf{2}^{2+}$ and $\mathbf{3}^{2+}$, the optimized geometry is to various extents characterized by a distortion of the electrophoric subunits, with a decrease of the $C(\gamma)-C\left(\gamma^{\prime}\right)$ distance. This configuration is a result of the hybridization change of $\mathrm{C}(\gamma)$ atoms from $\mathrm{sp}^{2}$ to $\mathrm{sp}^{3}$, reflecting the formation of the inter-pyridinium bond. As compared to the length of the analogous covalent bond $d\left(\mathrm{C}_{\mathrm{sp} 3}-\mathrm{C}_{\mathrm{sp} 3}\right)$ calculated in ethane (1.524 $\AA$ vs. $1.535 \AA$ experimentally measured by $x$-ray diffraction) or, more pertinently, in acenaphthene (1.558 ̊; Table S2 in SI), the calculated bond between the two $\mathrm{C}(\gamma)$ atoms is significantly elongated, thereby confirming its relative weakness. Typically, in the case of $\mathbf{2}^{0}$, it is estimated that the length of this electrochemicallyformed strained bond is $1.647 \AA\left(d\left(\mathrm{C}_{\mathrm{sp} 3}-\mathrm{C}_{\mathrm{sp} 3}\right) \mathrm{calcd}\right.$. $)$ and is characterized by an associated harmonic stretching force constant which is about 70\% that of a usual C-C sigma bond (see Table S2 in SI). In fact, as is the case for the SupLUMO, the spatial expanse of the HOMO naturally encompasses the electrophoric components. The bond-length alternation (BLA) pattern computed for the heterocyclic fragments in going from $\mathbf{2}^{2+}$ to $\mathbf{2}^{0}$ (Table S1.1 in SI), namely the shortening of $d(C(\alpha)-C(\beta)$ ) (from 1.377 to $1.347 \AA$ ) with concomitant elongation of $d(\mathrm{~N}-\mathrm{C}(\alpha)$ ) (from 1.348 to $1.382 \AA$ ) and $d(C(\beta)-C(\gamma))$ (from 1.348 to $1.506 \AA)$, reflects the emerging quinoidal structure that develops in $\mathbf{2}^{0}{ }^{16 \mathrm{~b}}$ This loss of aromaticity of the pyridinium rings is indicative of their actual involvement in the reduction. ${ }^{16 \mathrm{~b}}$ For consistency, we found it more convenient to refer to the HOMO of superelectrophore 2 in its $[z-2]$ state $\left(i . e . \mathbf{2}^{0}\right)$ as the SupHOMO. The observation that the SupLUMO of $\mathbf{2}^{2+}$ and the SupHOMO of $\mathbf{2}^{0}$ essentially have the same spatial expanse and involve essentially the same part of the super-electrophoric assembly 
further substantiates the notion of an "electron reservoir" (i.e. that the electrons are removed from the same place (SupHOMO) that they were initially stored (SupLUMO)) .

At this point, we recall that multi-[n]-center $(n>2)$ delocalization of like charges is an efficient means to minimize adverse "on-site" Coulomb repulsion, which can be achieved here via the extension of the bonding SupLUMO beyond the two primarily-concerned $\mathrm{C}(\gamma)$ centers. This is indeed achieved here due to the involvement of the $\mathrm{C}(\gamma) \mathrm{p}_{z}$ AOs in (i) the parent LUMOs of pyridinium units (in-plane $\pi$-type overlap), and (ii) in the through-space interannular bonding interaction (out-of-plane sigma-type overlap). If what we define as the "reservoir" is restricted only to the interannular component, the spread of the SupLUMO/HOMO onto the pyridinium moieties can be considered as "leaking" of this reservoir. Through this leaking, the reservoir itself hosts less than two electrons, contributing to its weakened nature. Alternatively, if we define the reservoir as an assembly comprising both pyridinium units together with the interannular bond, the formation/cleavage of the interannular bond itself is therefore the tipping element that regulates the function of the electron reservoir assembly. For further general considerations concerning the quantum mechanical description of the reservoir bond see SI (Section S7.2) and for what concerns the optimized geometry and fate (such as dimerization) of the singly-reduced mono-electrophoric reference species (1*), see SI (Section S10.2). Now, it is worth considering the case study of 3 . Within 3 in its native state $\left(3^{2+}\right)$, the pyridinium rings are not strictly cofacial, but adopt canted position towards each other, such that the critical vdW close contact at sites $\gamma / \gamma^{\prime}$ is preserved. It remains nonetheless that $\beta / \beta^{\prime}$ sites are also found lying at distances smaller than $3.4 \AA$. Beyond 
accurately reproducing above-mentioned experimental interatomic distances, molecular modeling reveals that in its doubly-reduced state $\left(3^{0}\right)$, the cyclophane-like superelectrophore exhibits three $\left(1 \gamma / \gamma^{\prime}+2 \beta / \beta^{\prime}\right)$ bonding interactions (see Table S1.2 in SI) as a result of the double cross clamping of the two heterocycles ensured by the butylene bridge and the newly formed $\gamma / \gamma^{\prime}$ bond. This means that there is a 2-electron/6-center covalent pancake bonding network within $\mathbf{3}^{0}$ instead of a regular 2-electron/2-center covalent bond, as is the case within $\mathbf{2}^{0}$. This finding explains why the electrochemically formed elongated $\gamma / \gamma^{\prime}$ bond is paradoxically characterized by a force constant ca. 30\% larger than that computed for the C-C sigma bond of ethane while this $\gamma / \gamma^{\prime}$ bond is even more elongated (i.e. weakened) than that in $2^{0}$ (i.e. $1.671 \AA$ versus $1.647 \AA$; cf. also IR frequencies: $854 \mathrm{~cm}^{-1} \mathrm{Vs} .891 \mathrm{~cm}^{-1}$, respectively; Table S2). In fact, the calculation mode of the force constant (see Experimental section in SI), that involves ancillary bonding interactions (pancake bonding), explains the greater value of the $\gamma / \gamma^{\prime}$ force constant associated to $3^{0}$ as compared to that of $2^{0}$.

From the standpoint of molecular design, it follows from this finding that choosing a "pancake" bond" as electron reservoir is not relevant if one envisions relying on a mechanical stress to exert a (remote) control of the charging/discharging process of the structronic functional assembly (i.e. the formation/cleavage of the reservoir bond on demand). This is not only due to the increase of the effective force constant associated to the reservoir bond (see Table S2 in SI), but is also related to the low magnitude of the redox-induced electro-structural relaxation ("breathing") that limits the degree of freedom for mechanical interplay (as compared to 2 ). These are the major 
justifications for the selection of a 2-electron/2-center bond as electron reservoir (see section 2 devoted to molecular design).

\subsection{Solution Study.}

3.4.1. NMR Characterizations. ${ }^{1} \mathrm{H}$ and ${ }^{13} \mathrm{C}$ NMR studies allowed the investigation of the structural features of $\mathbf{2}$ (and $\mathbf{1}$ ) in $\mathrm{CD}_{3} \mathrm{CN}$ solution in their native and chemically reduced forms. The ${ }^{1} \mathrm{H}$ NMR signature of the dipyridinium derivative $\mathbf{2}^{2+}$ exhibits sharp signals of its protons at $298 \mathrm{~K}$ indicating fast fluxional changes at the NMR timescale that include rotational motion of the two pyridinium rings and backbone distortion of the naphthalene scaffold. As a result, $\mathbf{2}^{2+}$ exhibits an averaged $C_{2 V}$ symmetry in solution at room temperature. After reduction of $2^{2+}$ in $\mathrm{CD}_{3} \mathrm{CN}$ solution with sodium amalgam, $\mathrm{Na}(\mathrm{Hg}) \quad\left(E^{0}=-1.95 \pm 0.01 \mathrm{~V}\right.$ VS SCE in MeCN $), 30$ the recorded ${ }^{1} \mathrm{H}$ NMR spectrum also showed sharp signals, which is indicative of the diamagnetic nature of $\mathbf{2}^{0}$, resulting from the spin pairing (i.e. the antiferromagnetic coupling) of heterogeneously transferred electrons. The two doublets at 8.31 and $7.73 \mathrm{ppm}$, ascribed to protons $\alpha$ and $\beta$ in the native form, are now observed at 6.01 and $4.17 \mathrm{ppm}$, lying in the frequency region of ethylene compounds. These noticeable upfield shifts $(\Delta \delta)$, that amount to 2.30 and $3.56 \mathrm{ppm}$, respectively (see Figure 2), are consistent with the loss of aromatic structure for the two pyridiniums, which adopt a quinoidal structure upon reduction. Further support stems from the ${ }^{13} \mathrm{C}$ NMR experiment thanks to the sensitive chemical shift of the $C\left(\gamma / \gamma^{\prime}\right)$ carbon nuclei, switching from the aromatic frequency domain $(\delta=160.1 \mathrm{ppm})$ in the native form, $2^{2+}$, to the aliphatic region ( $\left.\delta=60.1 \mathrm{ppm}\right)$ in the twoelectron reduced form $\mathbf{2}^{0}$, corresponding to a tremendous - yet feasible - change in the chemical shift of 100 ppm (see 
Figure $\mathrm{S} 4$ in SI). This observation is fully consistent with outcomes of ab-initio calculations that predict a change in the chemical shift, $\Delta \delta$, of 102.9 ppm for $C(\gamma$ ) (from 172.2 for $\mathbf{2}^{2+}$ to $69.3 \mathrm{ppm}$ : see Figure $\mathrm{S} 4$ in SI). This upheaval accurately reflects the change of hybridization of the $\mathrm{C}\left(\gamma / \gamma^{\prime}\right)$ carbon atoms from $\mathrm{sp}^{2}$ to $\mathrm{sp}^{3}$ that accompanies the electrochemically gated interannular covalent bond formation.31 In addition, through variable temperature NMR experiments we probed the stability of the newly formed 5membered ring. Even at $333 \mathrm{~K}$, no signal change or broadening (for instance, from a homolytic rupture of the new $\mathrm{C}_{\mathrm{sp} 3}-\mathrm{C}_{\mathrm{sp} 3}$ bond) was observed that could be attributed to intervening paramagnetic species. In fact, we will show below that the singly reduced radical intermediate cannot accumulate because of potential inversion ${ }^{32}$ (Section 3.5.2.2). Not only is the radical cation too short-lived compared to characteristic time of NMR (around a few seconds) but also observation that no radical species could be detected upon heating is informative regarding the relative robustness of the reservoir bond.

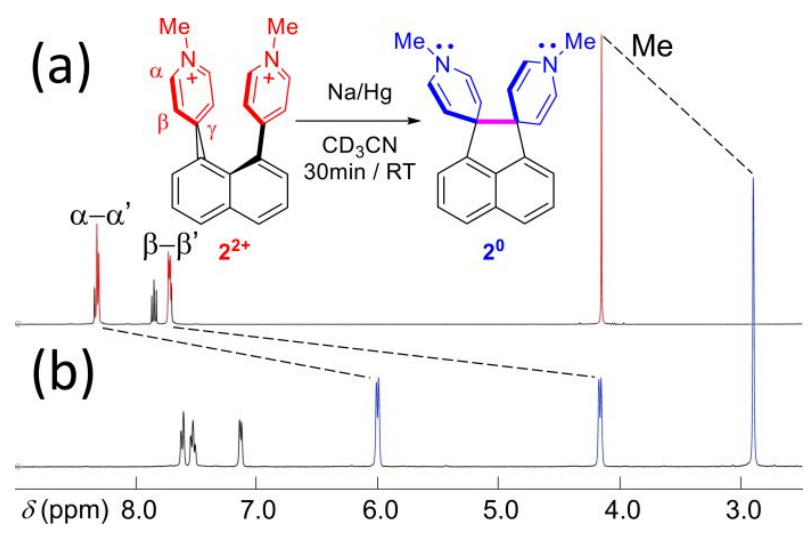

Figure 2. ${ }^{1} \mathrm{H}$ NMR spectra $\left(400 \mathrm{MHz}, \mathrm{CD}_{3} \mathrm{CN}, 298 \mathrm{~K}\right)$ of $2\left[\mathrm{PF}_{6}\right]_{2}\left(\mathrm{C}=10^{-2} \mathrm{~mol}\right.$ $\mathrm{L}^{-1}$ ) before (a) and after (b) chemical reduction, showing the diagnostic chemical shift of the $\mathrm{H}\left(\alpha, \alpha^{\prime}\right), \mathrm{H}\left(\beta, \beta^{\prime}\right)$ and $N$-Me protons of the electrophoric subunits; see also section S29 in SI.

As far as the native form of the reference species $1\left[\mathrm{PF}_{6}\right]$ is concerned, similar conclusions can be drawn from the ${ }^{1} \mathrm{H}$ and ${ }^{13} \mathrm{C}$ 
NMR spectra regarding their fluxional (and averaged) structures. However, contrary to the previous case, after reduction of $1\left[\mathrm{PF}_{6}\right]$ in $\mathrm{CD}_{3} \mathrm{CN}$ with $\mathrm{Na} / \mathrm{Hg}$, a more complex spectrum is obtained (Figure S5) where protons of the scaffold are more affected than those of pyridinium (see Section S12.2), corresponding to a mixture of compounds among which is the $\alpha-\alpha$ (i.e. 2-2; Table S3 in SI) dimer ([1] 2) that is computed to be the most stable (see Table s4). Once again, no effect ascribable to the presence of radical $\mathbf{1}^{\text {' could be }}$ evidenced. In fact, upon chemical reduction, whether considering the cases of $\mathbf{1}\left[\mathrm{PF}_{6}\right]$ or $\mathbf{2}\left[\mathrm{PF}_{6}\right]_{2}$, there is sufficient time for chemistry to fully develop, which is not necessarily the case with potentiodynamic electrochemical methods.

\subsubsection{In situ Spectroelectrochemical (SEC) Studies.}

Spectroelectrochemistry has the twofold advantage over its chemical counterpart (e.g. the use of $\mathrm{Na} / \mathrm{Hg}$ amalgam or cobaltocene for reduction purposes) that the potential energy of electrons as "reactants" can be continuously varied and their availability controlled over time. Great assets of SEC stem from the potential control of electron availability, that is, the monitoring of a given redox process. In this sense, the probed phenomena are not necessarily the same as those observed by chemical means.

The UV-Vis-NIR electronic absorption SEC study was performed with 1 millimolar solutions of $\mathbf{1}\left[\mathrm{PF}_{6}\right]$ and $\mathbf{2}\left[\mathrm{PF}_{6}\right]_{2}$ in $0.1 \mathrm{M}$ $\mathrm{TBAPF}_{6}$ in MeCN (Figure 3-top). Regarding the electronic spectrum of $2\left[\mathrm{PF}_{6}\right]_{2}$, three main absorption bands are observed in the near UV region that are characterized by maxima at 221 $\mathrm{nm}, 253 \mathrm{~nm}$ and $357 \mathrm{~nm}$. These absorption features are accurately reproduced by TD-DFT calculations (vide supra) that allowed the assignment of electronic transitions (Figure 3-bottom). The first two higher-energy bands (with simulated maxima at 218 and $247 / 253 \mathrm{~nm}$ ) are $\Pi_{-*} \Pi^{*}$ transitions centered 
on the naphthalene scaffold and on the pyridinium subunits, respectively (see Table $\mathrm{S} 6$ and Figure $\mathrm{S} 8$ in SI). Most importantly, the third, lowest-lying band (i.e. the red-edge feature), calculated at $386 \mathrm{~nm}$, is assigned to a single electronic transition of HOMO-SupLUMO character, demonstrating dominant (99 \%) charge transfer (CT) character from the electron-rich naphthalene moiety to the virtual SupLUMO. This latter is specific to the two-pyridinium "supramolecular" assembly (see Table S6 and Figure S8). Indeed, as far as the lowest-lying virtual MO of the superelectrophore is concerned, the two heteroaromatic moieties are essentially through-space coupled, with virtually no electronic interaction mediated through the bonds of the naphthalene scaffold (see Figure 1), insofar as it behaves as a cross-conjugated platform when considering the 1,8connectivity. ${ }^{29}$ This CT band is therefore a diagnostic feature supporting the existence of the target SupLUMO. The spectrum of the two-electron-reduced species, $\mathbf{2}^{0}$, characterized by only two major absorption bands at 228 and $295 \mathrm{~nm}$, is obtained upon varying the applied potential down to $-1.20 \mathrm{~V}$ (vs. quasi-reference electrode $\mathrm{Ag} / \mathrm{AgCl})$. As is the case for the native state, the TD-DFT simulated spectrum of $\mathbf{2}^{0}$ compares very well with the experimentally recorded trace, with two bands of calculated maxima at 224 and $295 \mathrm{~nm}$, respectively. Theory tells us that the latter results from a pure $\Pi-\Pi^{*}$ transition centered on the naphthalene unit, as confirmed by the structured shape (vibrational progression) experimentally observed for the lowest-energy band. The observation that the lowest-energy band of CT nature, evidenced for 2 in its native state, is no longer present in the spectrum of $\mathbf{2}^{0}$, is in line with the concept that the two-pyridinium electrophoric assembly switches from being electron-deficient (within $\mathbf{2}^{2+}$ ) to electron-rich (within $\mathbf{2}^{0}$ ) upon reduction. Lastly, we emphasize the isosbestic points at 215, 241, 279 
and $311 \mathrm{~nm}$ observed during the course of the reductive SEC experiment, and that the spectrum of the super-electrophore in its native form $\left(2^{2+}\right)$ is restored upon reoxidation, showing the same isosbestic points (see Figure S6 in SI). This observation is consistent with the below-established electrochemical cyclability (i.e. chemical reversibility) that relies on both processes of two-electron reduction and oxidation (see section 3.5.2.1). It is worth noting that the results of the FTIR vibrational absorption (SEC) study further substantiate outcomes of the UV-vis SEC by evidencing the bond-length alternation (BLA) attached to the quinoidal form of the reduced pyridylium components within $\mathbf{2}^{\mathbf{0}}$ and by confirming the chemical reversibility of the redox transformation $\mathbf{2}^{\mathbf{2 +}} / \mathbf{2}^{\mathbf{0}}$ (see section $\mathrm{S} 21$ in $\mathrm{SI}$ ).
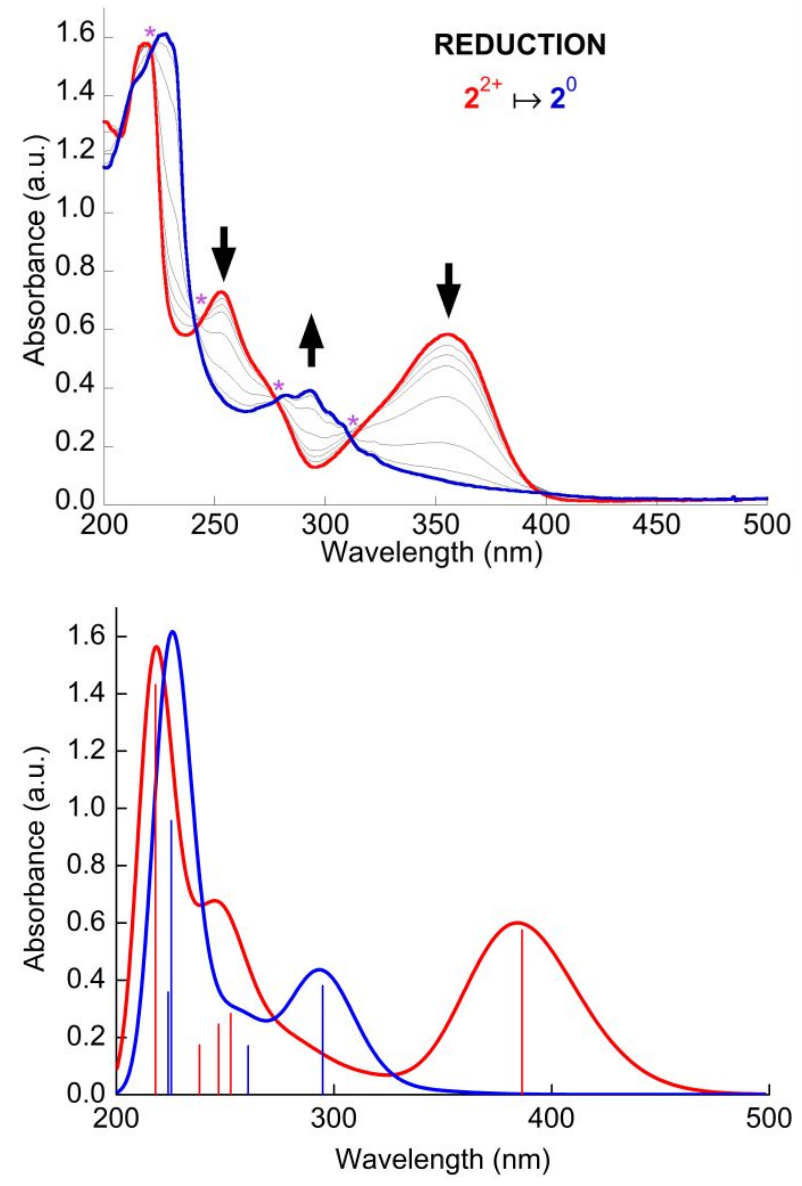

Figure 3. (Top) Spectroelectrochemical UV-vis experiments of a solution

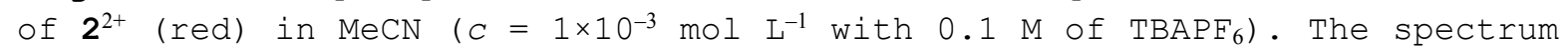
of $\mathbf{2}^{0}$ (blue) is obtained after achieving potential of $-1.2 \mathrm{~V}$ against $\mathrm{Ag} / \mathrm{AgCl}$ quasi-reference electrode (reduction process). Asterisks (*) 
indicate isosbestic points. (Bottom) Simulated absorption spectra of $\mathbf{2}^{2+}$ (in red) and $\mathbf{2}^{0}$ (in blue). Spectra are obtained by convolution with Gaussian functions centered at calculated absorption energies with a fixed full width at half maximum of $0.45 \mathrm{eV}$. Intensities were normalized with respect to the experimental peak at $360 \mathrm{~nm}$.

Based on the remarkable agreement between the experimental results recorded by UV-Vis SEC and computed data obtained from the TD-DFT modeling, we may confidently deduce that: (i) the CT band identifies the SupLUMO in $\mathbf{2}^{2+}$, (ii) isosbestic points indicate that there is a clean and direct transformation of $\mathbf{2}^{2+}$ into $\mathbf{2}^{0}$, consistent with the single-step build-up of the reservoir bond (in line with the NMR study, Section 3.4.1). Furthermore, the overall chemical reversibility of the electrochemical process is established through the recovery of the starting absorption spectrum of native $\mathbf{2}^{2+}$ upon re-oxidation of $\mathbf{2}^{0}$ (see Figures $\mathrm{S} 6$ and $\mathrm{S} 7$ in SI) .

Roughly the same overall behavior is observed in the case of $1^{+}$even if spectral changes upon in-situ processes of reduction and re-oxidation are less pronounced (in particular regarding contributions from charge-transfer excitations) than in the case of the dipyridinium derivative (see Figure S9 in SI). This finding is not surprising: a single electrophoric subunit rather than the "synergistic assembly of two coupled pyridinium subunits" is involved. The observed reversibility of the SEC behavior is consistent with the electrochemical behavior (see below, section 3.5.2.1), which shows that, when formed as a minor reduction product at low potential scan rate (i.e. $v \leq 0.225 \mathrm{~V} \mathrm{~S}^{-1}$ ), the dimer is indeed oxidatively cleaved ( $\mathrm{Ox}-2$ process in Figure 5-top) and the starting electrophore, $\mathbf{1}^{+}$, is recovered. The presence of isosbestic points (Figure S9) is compatible with the formation of both the radical species (1*) and the dimer [1] 2 to the extent that their calculated spectral signatures are very similar (see Figures $\mathrm{S} 9$ and $\mathrm{S} 10$ in SI). 


\subsection{Mechanistic Study.}

\subsubsection{Potential Inversion and Bond Formation: Insights from}

Computational Modeling. Comparison of the MOs represented in Figure 1 suggests that the process of interannular covalent bond formation, which occurs inside super-electrophores 2 and 3, is fundamentally different from the bimolecular process of dimerization. The first added electron enters the SupLUMO and is delocalized across both pyridinium units (i.e. not localized on a single pyridinium as would be the case for a genuine "inner" sigma dimerization). Only a slight structural change is computed for the first electron transfer, whereas the second electron transfer is clearly accompanied by a pyramidalization of each of the two $C(\gamma)$ atoms. This unambiguously confirms the change of their hybridization from $\mathrm{sp}^{2}$ to $\mathrm{sp}^{3}$.

As regards the prototype two-pyridinium super-electrophore, 2, the comparison of the respective energies (Figure 1) of

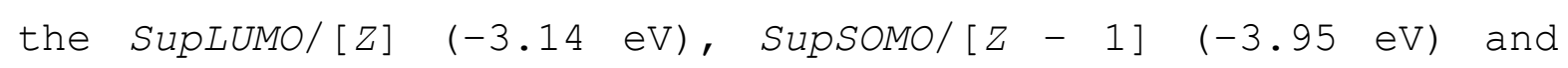
SupHOMO/[Z - 2] $(-5.12 \mathrm{eV})$ reveals that stabilization energy attached to the second heterogeneous electron transfer $(\triangle E=$ $-1.17 \mathrm{eV})$ is greater than that attached to the first electron transfer $(\Delta E=-0.81 \mathrm{eV})$. Bearing in mind that bond formation is usually considered a barrierless process, 33 this means that the second one-electron reduction process is expected to be "easier" than the first one. To some extent, this finding can be viewed as an indication of an inversion of potentials for the chemical bond formation, provided that one considers the super-electrophoric multicomponent system as a single electronic entity (this is justified by the through-space interaction of the two pyridiniums, which gives rise to the SupLUMO). This inversion is consistent with observation of a single-step two-electron reduction (see below, Red-1 in Figures 4 and 5). Now, the question is the extent to which 
the oxidative bond cleavage also leads to a similar inversion of oxidation potentials. Experimentally, one should therefore observe a single two-electron oxidation. In fact, this is in line with observation of the cyclic voltammograms of 2 (see below, Figure 5-bottom) and comparison of the derived semiintegrated neo-polarograms (see Figure S15 in SI). Brought together, these findings suggest that, from a mechanistic standpoint, both the bond formation and bond cleavage processes are a result of potential inversion phenomena.

\subsubsection{Mechanistic Insights into Potential Inversion of Bond Formation/Cleavage from Electrochemistry and Simulation of Cyclic Voltammograms.}

3.5.2.1. Electrochemical Study. Electrophores $\mathbf{1}^{+}$and $\mathbf{2}^{2+}$ were derivatized with redox probes that undergo a monoelectronic redox process $(n=1)$, namely ferrocene (FC) units that are appended via saturated propylene linkers at $\mathrm{N}_{\text {pyridinio }}$ atoms (1FC ${ }^{+}$ and $\mathbf{2} \mathbf{F c}^{2+}$ in Chart 3). Cyclic voltammograms (CVs) at a stationary electrode and linear sweep voltammograms (LSVs) at a rotating disk electrode (RDE) are shown in Figure 4. Comparison of the LSV wave heights for electrophores identical to $\mathbf{1}^{+}$and $\mathbf{2}^{2+}$ and that of FC probes confirms that the number $(n)$ of electrons involved in the reduction processes (Red-1) is equal to the number of FC units, that is, $n=1$ and 2 for $\mathbf{1} \mathbf{F c}^{+}$and $\mathbf{2} \mathbf{F c}^{2+}$, respectively. ${ }^{34} \mathrm{CVS}$ of $\mathbf{1} \mathbf{F c}^{+}$and $\mathbf{2} \mathbf{F c}^{2+}$ reveal sizably different behaviors (Figure 4). For $\mathbf{1} \mathbf{F c}^{+}$, one quasi-reversible redox process (Red-1/Ox-1) at $-1.278 \mathrm{~V}^{36}$ is observed along with an oxidation process $(\mathrm{Ox}-2)$ in the return scan at $E_{\text {pa-(Ox-2) }}=-0.362 \mathrm{~V}$, which is characterized by a much smaller peak current. For $\mathbf{2} \mathbf{F c}^{2+}$, the reduction (Red-1) is an irreversible process that occurs at a more positive potential than for $\mathbf{1} \mathbf{F C}^{+}\left(E_{\text {pc-(Red-1) }}=-1.002 \mathrm{~V}\right)$, which is also accompanied in the return scan by an irreversible oxidation process ( $E_{\text {pa-(Ox- }}$ 
2) $=-0.095 \mathrm{~V})$ that manifests itself as a well-defined broad peak characterized by a current intensity lower than the reduction peak (Red-1). The irreversible oxidation process $(\mathrm{Ox}-2)$ is not present in the first anodic scan (starting from $-0.6 \mathrm{~V}$ to $+1.0 \mathrm{~V})$ and appears only after the reduction process (Red-1) is complete. Such a sequence-dependence indicates that $\mathrm{Ox}-2$ is an electrochemical-chemical (E-C) process related to the oxidation of a reduction product of Red-1, which therefore also involves an E-C process (see below). Further, the anodic shift of the Red-1 reduction potential $\left(\Delta E_{\text {Red-l }}=+0.276 \mathrm{~V}\right)$ in going from $\mathbf{1} \mathbf{F c}^{+}$to $\mathbf{2} \mathbf{F c}^{2+}$ is consistent with the presence of an interaction between the two pyridinium units within $\mathbf{2} \mathbf{F} \mathbf{c}\left[\mathrm{PF}_{6}\right]_{2}$ and thus within $\mathbf{2}\left[\mathrm{PF}_{6}\right]_{2}$.
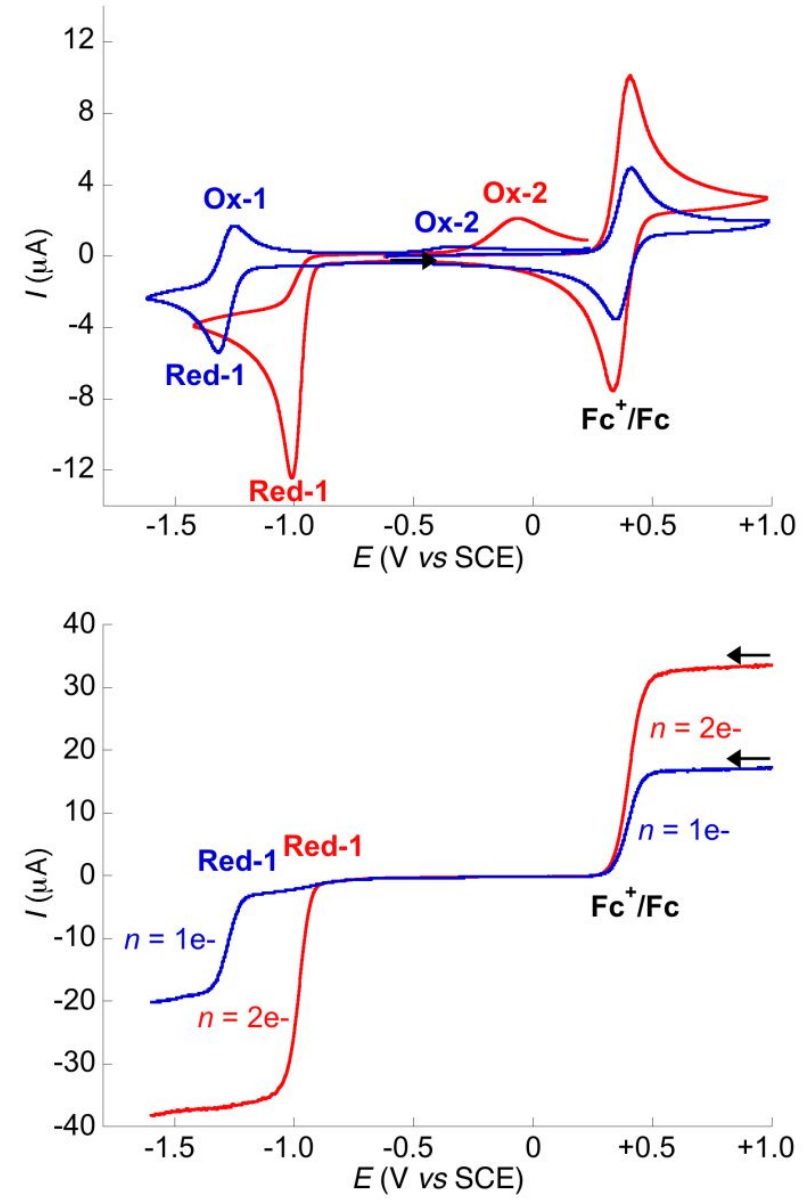

Figure 4. Cyclic voltammetry (top) and rotating disk electrode (RDE) experiments (bottom) of $\mathbf{1 F C}_{\mathbf{F}}\left[\mathrm{PF}_{6}\right]$ (blue traces) and $\mathbf{2} \mathbf{F C}\left[\mathrm{PF}_{6}\right]_{2}$ (red traces) solutions $\left(C \approx 5 \times 10^{-4} \mathrm{~mol} . \mathrm{L}^{-1}\right.$ in $\mathrm{MeCN}$ with $0.1 \mathrm{M}$ of $\mathrm{TBAPF}_{6}$ ) both recorded at scan rate $\mathrm{V}$ of $0.1 \mathrm{~V} \mathrm{~s}^{-1}$ and rotation speed $r$ of $2000 \mathrm{rpm} .{ }^{37}$ 
In order to get further insight into the very nature of $\mathrm{Ox}-2$ processes observed for one- and two-electron-reduced electrophores $\mathbf{1}^{+}$and $\mathbf{2}^{2+}$, we performed a potentiodynamic study as a function of the potential scan rate (v) (Figure 5).
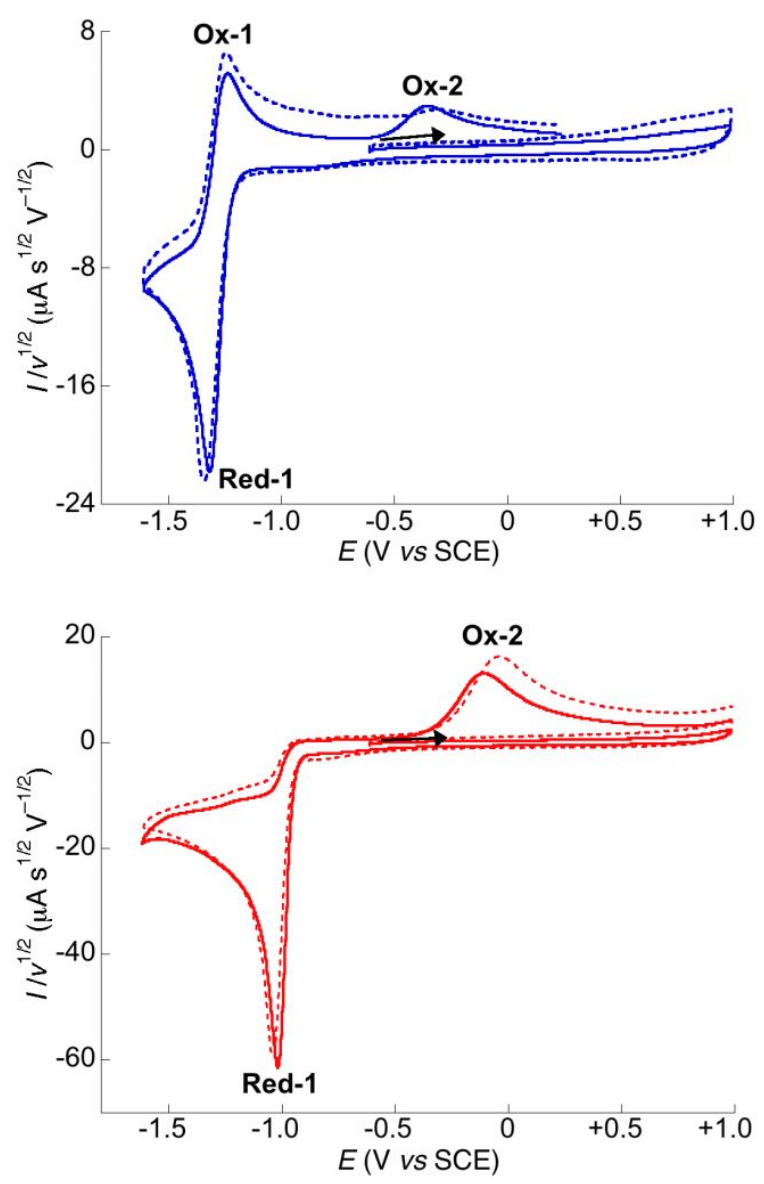

Figure 5. Cyclic voltammograms of $\mathbf{1}\left[\mathrm{PF}_{6}\right]$ (top; blue traces) and $2\left[\mathrm{PF}_{6}\right]_{2}$ (bottom; red traces) solutions $\left(C \approx 5 \times 10^{-4} \mathrm{~mol} \mathrm{L^{-1 }}\right.$ in MeCN with $0.1 \mathrm{M}$ of $T_{B A P F}$ ) recorded at $0.1 \mathrm{~V} \mathrm{~s}^{-1}$ (solid line) and at $0.625 \mathrm{~V} \mathrm{~s}^{-1}$ (dashed line). $\mathrm{CV}$ traces are normalized against the square root of the potential (applied voltage) scan rate $v \cdot{ }^{38}$

From comparison of CVS recorded at $0.1 \mathrm{~V} \mathrm{~s}^{-1}$ and $0.625 \mathrm{~V} \mathrm{~s}^{-1}$, one notices that the main difference stems from the status of the ox-2 process, which becomes virtually indiscernible at higher scan rate for $1^{+}$(ca. $V>0.225 \mathrm{~V} \mathrm{~S}^{-1}$ ) while it remains virtually unchanged for $\mathbf{2}^{2+}$ (this latter behavior was actually verified for $V$ values of up to $1000 \mathrm{~V} \mathrm{~s}^{-1}$ using an ultramicroelectrode setup). ${ }^{39}$ In other words, the Ox-2 
processes are clearly different in nature for redox-active species $\mathbf{1}^{+}$and $\mathbf{2}^{2+}$ and the insensitivity to potential scan rate observed for $2^{2+}$ clearly points towards a fast chemical process, and more precisely a process inner to the superelectrophore (i.e. the formation of the reservoir bond). In this case, it is worthwhile establishing the number ( $n$ ) of electrons involved in the ox-2 process of $\mathbf{2}^{0}$. This number is typically derived from semi-integration (i.e. convolution)40 of the $\mathrm{CV}$ of $2^{2+}$ recorded at $\mathrm{V}=0.1 \mathrm{~V} \mathrm{~S}^{-1}$ (see Figure $\mathrm{S} 15$ in Section S25.1 of SI), which here shows that $n$ is the same for the reduction (Red-1) and the return scan (Ox-2) processes, i.e. $n=2$, as expected. Besides, Section $\$ 25.1$ also reports the comparison of electrochemical behaviors of 2 and $\mathbf{3}$.

Conversely to 2 (and $\mathbf{3}$ ), the quasi-reversibility of the Red-1 process together with the scan rate dependence of $\mathrm{Ox}-2$ in the case of single-pyridinium electrophore $\left(\mathbf{1}^{+}\right)$are straightforwardly explained by intervening intermolecular process that requires the formation of pairs of reactive species (singly-reduced electrophores i.e. radicals $\mathbf{1}^{*}$ ). This is the well-documented dimerization process ${ }^{41-44}$ (electrochemical-chemical - $\mathrm{EC}_{\text {dim }}$ - mechanism) here giving most likely the ortho-ortho dimers [1]2 consistently with computational outcomes (see SI, Section S10.2) as well as observations out of the NMR study (see Section 3.4.1 and Figure S5).

\subsubsection{Electrochemistry and CV Simulation.}

Fast electron transfer followed by the dimerization of a radical intermediate is a common mechanism often encountered in the reduction of pyridinium-based derivatives. Dimerization is a bimolecular process, which is characterized not only by a positive shift of the redox potential of the product, as compared to that of parent single-pyridinium 
"monomers", but is also dependent on the bulk concentration.45 An archetypal example is the more than centennial synthetic route to methyl viologen (MV). ${ }^{46}$ The theory and application of the reduction-dimerization process was developed by Koutecký, ${ }^{47}$ Blunt, ${ }^{48}$ Olmstead ${ }^{49}$ and Savéant. ${ }^{50}$ However, abovedescribed experiments unambiguously established that reduction of $\mathbf{2}^{2+}$ (Red-1 in Figures 4 and 5 ) is not a one- but a two-electron process (see Section 3.5.2.1). Features, which distinguish the redox mechanism of $\mathbf{2}^{2+}$ from bimolecular dimerization are (i) the two-electron reduction, (ii) the independence of redox potentials on the bulk concentration, (iii) observation of $\mathrm{Ox}-2$ process at higher scan rates, (iv) spectroscopic proof of the bond formation inner to the superelectrophore (Section 3.4). These features confirm that the observed reduction mechanism of $2^{2+}$ is consistent with an inner process, namely the electrochemicalo-bond formation. Therefore, the reservoir-bond formation has nothing to do with an ordinary bimolecular dimerization. This agrees with theoretical calculations that pointed to the inner bond formation correlated with characteristic structural and electronic rearrangements (Section 3.3). The heterogeneous transfer of two electrons at apparently the same driving force, i.e. at the same applied potential, implies that the standard redox potentials $E_{1}^{0}$ and $E^{0}{ }_{2}$ for the transfer of each electron are either compressed (up to a coalescence) or even inverted (Section 3.2). Detailed analysis of the currentvoltage dependence obtained by the cyclic voltammetry at higher scan rates indeed confirms the potential inversion phenomenon (as suggested in sections 3.5.1 and 3.5.2.1). The voltammogram using the glassy carbon electrode (see section S26-A in SI) and the scan rate of $2 \mathrm{~V} \cdot \mathrm{S}^{-1}$ (Figure S21) yields similar semi-integrated "neo-polarograms" or "convolution voltammograms" as those shown in Figure S15. The separate 
semi-integration of each voltammetric half-cycle yields welldefined waves (Figure S22) reaching a limiting value of the semi-integral of the current, $m(t) \lim ,{ }^{51}$ and thus enabling the analysis of the wave shapes by the log-plot analysis:

$$
\log \frac{m(t)}{m(t) \lim -m(t)} \text { vs. } E
$$

The two-electron reduction yields the log-plot trace featuring an S-shaped curve, having two linear asymptotes with the same slope of $59 \mathrm{mV} /$ decade, as is expected for two, fast, one-electron transfers. This allows not only the estimation of the two standard potentials, $E^{0}{ }_{1}$ and $E^{0}{ }_{2}$, but also provides the demonstration that these latter are inverted (Figure 6). The difference $\left|E_{1}^{0}-E^{0}{ }_{2}\right|=60 \mathrm{mV}$ is obtained both at lower and at higher voltage scan rates 10.06 $\left.\mathrm{V} \cdot \mathrm{s}^{-1} \leq \mathrm{V} \leq 2 \mathrm{~V} \cdot \mathrm{s}^{-1}\right)$. This insensitivity of the voltage difference with respect to $V$ was further verified by numerical fitting of a series of voltammograms by application of the finite difference techniques. Furthermore, it is worth noting that the magnitude of the experimentally derived potential inversion (ca. $60 \mathrm{mV}$ ) is in line with the computational estimate (ca. $40 \mathrm{mV}$; see Section $\mathrm{S} 7.3$ in SI).

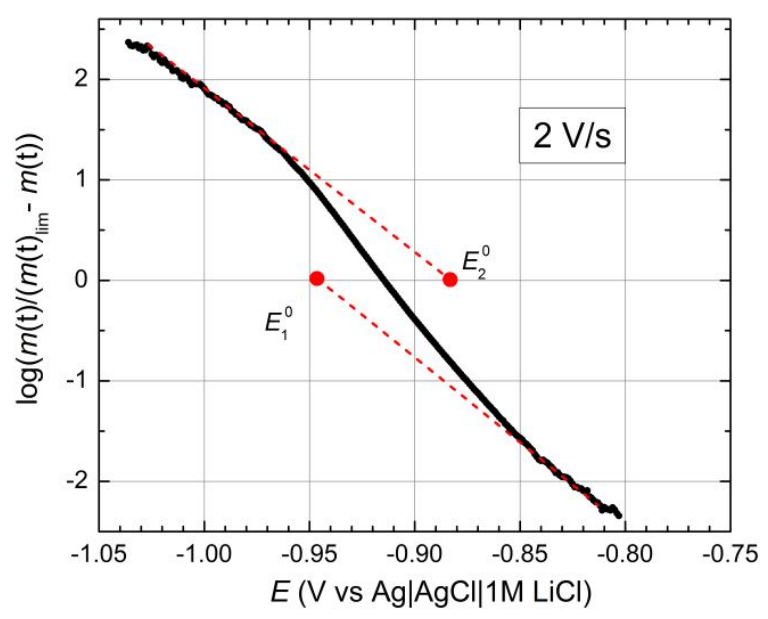

Figure 6. Log-plot analysis of semi-integrated neo-polarogram (Figure S22) calculated for the reduction step $\left(0.5 \mathrm{mM}^{2+}\right.$ and $\mathrm{TBAPF}_{6} 0.1 \mathrm{M}$ in MeCN, glassy carbon electrode, scan rate $\left.2 \mathrm{~V}^{-1}\right)$. Extrapolation of two asymptotes to y-axis $=0$ yields two redox potentials for the first $E^{0}{ }_{l}$ and the second $E^{0}{ }_{2}$ electron transfer step. The potential difference $\left|E_{1}^{0}{ }_{1}-E_{2}^{0}\right|$ is $60 \mathrm{mV}$. 
An analogous log-plot analysis applied to the oxidation wave $(\mathrm{Ox}-2)$ is not that straightforward. This peak, observed in the return scan regardless of potential scan rates, is indeed rather small due to the diffusion of the neutral $\sigma$-bonded reduction product toward the bulk. The lack of a reduction counterpart for the oxidation process ox-2 of the $\sigma$-bonded form indicates that this inner-sphere $\sigma$-bond cleavage is a fast and irreversible process (see section S26-B in SI). This is in line with the assumption that the $\mathrm{Ox}-2$ process regenerates the electrophore in its starting (native) form, $2^{2+}$.

The digital simulation of CVs by finite difference methods considered two possible reaction schemes differing in sequences of electron transfers (E) and the chemical reaction (C, here the $\sigma$-bond formation and cleavage). The overall electrochemical reaction is usually referred to as an EEC process and is represented in Chart 4 a where $\mathbf{A}_{\mathbf{2}}{ }^{2+}$ and $\mathbf{B}_{\mathbf{2}}{ }^{0}$ stand for $\mathbf{2}^{2+}$ and sigma-bonded $\mathbf{2}^{0}$. Alternatively, the structural change (i.e. the bond cleavage) could take place right after the first electron withdrawal, as it is shown in Chart $4 \mathrm{~b}$. The latter case would be termed an ECE mechanism. The equilibrium constants and chemical rates are $K_{1}=k_{1} / k_{-1}$ and $K_{2}=$ $k_{2} / k_{-2}$. 
(a)

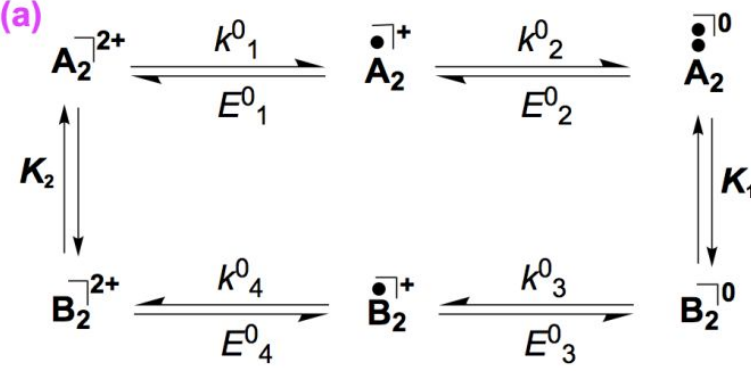

(b)

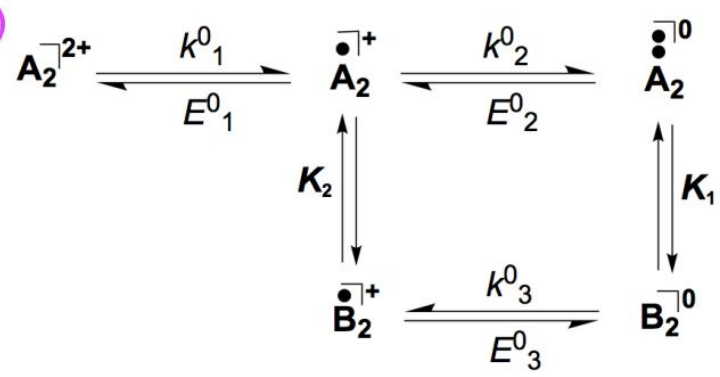

Chart 4. Reaction scheme involving the two-electron reduction and reoxidation with a coupled chemical reaction (EEC mechanism for both steps; top, (a)); The EEC mechanism applies for the reduction, whereas ECE pathway holds for the oxidation (bottom, (b)). The point is that for both (a) and (b) schemes, forward pathway to $\mathbf{B}_{2}{ }^{0}$ is different from backward pathway, which is the sine qua none condition for obtaining electrochemical hysteresis supporting electron storage; $k_{n}^{0}$ are standard rate constants of heterogeneous electron transfers.

Since the digital simulation analysis of the oxidation wave allows unambiguously identifying of two redox potentials $E_{3}{ }_{3}$ and $E^{\prime}{ }_{4}$ the reaction mechanism most likely involves the EEC scheme with potential inversion (Chart $4 a$ ) for both the reduction ( $\mathrm{Red}-1)$ and the oxidation (Ox-2) steps. The fitting of voltammograms recorded over a wide range of v-values, usually confirms the nature of the reaction scheme. ${ }^{52}$ Both reaction mechanisms contain a large number of kinetic parameters and equilibrium constants. This raises issues regarding the reliability of fitting outcomes insofar as several combinations of adjustable parameters may give similar results. It is therefore worthwhile getting an estimate at least of some of the input parameters (see Section 3.5.2.1 and Section S26 in SI).

An example of calculated data that quite accurately fit experimental data is given in Figure S26 (see also Table S11 in $S I)$. Fitting indeed reasonably reproduced the $i_{d} / i_{c}$ ratio 
(Figure S27), the potential differences $\left(E_{1}^{0}-E_{2}^{0}\right)=71 \mathrm{mV}$ and $\left(E^{0}{ }_{3}-E^{0}{ }_{4}\right)=141 \mathrm{mV}$ as well as fulfilling additional conditions stated in section s26. Most importantly, not only did this simulation distinguish between $E_{3}^{0}$ and $E_{4}^{0}$, it also demonstrated that potential inversion is at work for the bond cleavage, as is the case for the bond formation.

In summary, the combination of electrochemical experimental and fitted data indicates that both the reduction (Red-1) and the oxidation (Ox-2) obey the EEC mechanism given in Chart 4a. Finally, pathways for reduction and oxidation are however different with respect to the involved redox-active species (A/B in Chart 4a), thereby accounting also for the experimentally evidenced electrochemical hysteresis. Chart 5 explicitly summarizes the two-electron reduction/oxidation cycles operative, with a two-way potential inversion for super-electrophore 2 (and also 3).

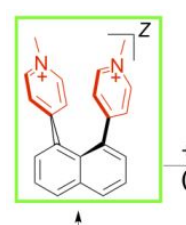

(C) E-S Relax.

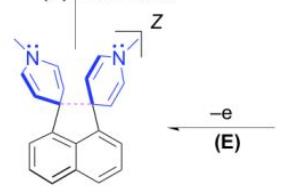

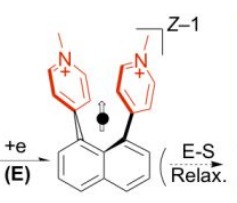

E-S

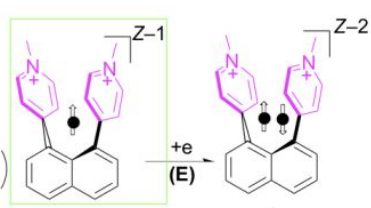

(C) E-S Relax
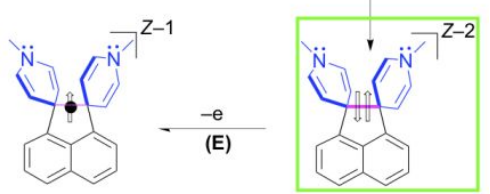

Chart 5. The pictorial representation of the mechanism underpinning the working principle of the structronic electrochemical paradigm thoroughly investigated in the present work. The functional assembly (2) referred to as a structronic prototype is akin to a kind of 3-dimensionnal MV (" $3 D$ MV") but displaying an electrochemical behavior sharply different from that of the 2D, MV benchmark species.

\subsection{Insights gained from other instances of electrochemically-gated Carbon-Carbon bonds within organic systems.}

First of all, it's worth noting that, contrary to 3 that relies on cross clamping to tune electrochemical hysteresis (see section S25.1 in SI), assemblies reported in this 
section rely on two other steric constraints that are namely the front strain as well as the back (remote) strain (see Chart 2c). So, interestingly, there exist connections between the applied field of molecular-based electrochromism, 53 that is, the molecular-level optical switching (output) controlled by an electrochemical input, and the basic research efforts devoted to the exploration of "ultralong $\mathrm{C}-\mathrm{C}$ bonds and of their limits",54,55 that are, actually, beyond ${ }^{56-58}$ expectations. 59,60 The above-mentioned connection stems from the intriguing electrochemical phenomenon referred to as "Dynamic Redox" (DyRex) behavior, $54,55,61$ also referred to as "intramolecular switching of single bonds"62 (Chart S1 in SI). Namely, it was shown that covalent assemblies properly incorporating couples of redox-active units can give rise to the formation of a $\left(\mathrm{C}_{\mathrm{sp} 3}-\mathrm{C}_{\mathrm{sp} 3}\right)^{63}$ carbon-carbon bond that bridges electrochemically active components following a reductive or an oxidative process. For example, typically integrated redox-active chromophoric units are trityliums, 53,61,64 heterotricyclic hydrocarbons, ${ }^{65,66}$ thiophenes, ${ }^{67}$ or octamethoxytetraphenylene. ${ }^{68}$ of particular interest is the case of bis-acridinium assemblies (e.g. Chart sla) that are more or less tightly pre-organized with various semi-rigid to rigid scaffolds, i.e. biphenyl, naphthalene, acenaphthene and acenaphthylene. ${ }^{54,69}$ Structural evidences were collected from crystallographic studies (single-crystal X-ray diffraction) establishing (i) the reality of the elongated nature of the newly formed $\mathrm{C}_{\mathrm{sp} 3}-\mathrm{C}_{\mathrm{sp} 3}$ sigma bonds $(\mathrm{d}(\mathrm{C}-\mathrm{C})>1.69 \AA$ vs. $1.54 \AA$ for ethane) and (ii) the existing relationship between these bond-lengths and both the "front strain" due to interelectrophoric steric hindrance and the "back strain" giving variously distorted scaffolds. Such experimental data are not available from our own study in spite of our trials for crystallizing $\mathbf{2}^{0}$. The important point here is that acridinium 
is closely affiliated to pyridinium as regards its electrochemical/electrophilic activity at the $\mathrm{C}(\gamma)$ site, that corresponds to the $\mathrm{C}(9)$ position of the acridinium (Chart Sla). However, they sharply differ in their reactivity at either side of the $\mathrm{N}_{\text {pyridinio }}$ atom (i.e. ortho $\mathrm{C}(\alpha)$ sites of pyridinium motif). In the case of acridinium, the presence of two edge-fused lateral rings, i.e. dibenzoannulation, at one and the same time prevents from the above-mentioned detrimental ortho reactivity (including nucleophilic addition), and strengthens the chemical stability of the pyridinium core (otherwise likely to undergoing ring opening). ${ }^{55}$ In fact, we were sharing in these respects the same concerns as Suzuki and coworkers, especially about ortho (C2 and C6) reactive positions of pyridinium. ${ }^{4}$ Originally, we were considering the "naked" pyridinium derivative $\left(\mathbf{2}^{2+}\right)$ as a non-optimized demonstrator compound, likely to be subsequently improved by ensuring its ortho protection with some bulky substituents. The present work demonstrates that such a protection was, in fact, superfluous thanks to the effects of the synergistic interplay of electrophoric units. Although specifically implemented as a key-ingredient of the design of structronic devices, this synergy was finally found to be more efficient than initially planned i.e. its impact on reactivity had been underestimated (Chart 2c). Indeed, we found that the "SupLUMO" of $2^{2+}$ was functioning as a genuine attractor that diverts or traps the whole reactivity of classical (i.e. isolated) pyridinium.

For a further thorough comparative discussion of Dyrex systems with super-electrophores described in the present work, see Section S27 in SI.

\section{Summary and Conclusions.}


The reactivity of pyridinium components within 2 (and 3) was found to be heavily impacted compared to that of naked pyridinium or to a mono-pyridinium model species like 1 . The synergistic interplay of the two electrophoric units allows both (i) emergence ${ }^{70}$ of the SupLUMO, which acts as a "reactivity sink" towards the target reservoir-bond formation inner to the super-electrophoric assembly and (ii), the protection of the super-electrophore from side reactions, like is intermolecular $\alpha$-dimerization. The lack of reactivity at $\alpha$ sites of these pyridinium moieties within the 3-D structronic construct is reminiscent of that of the wellknown 2-D (roughly planar) covalent MV species (as a oneelectron redox shuttle or mediator). However, depending on the nature of electrophores, the manner by which the two electrons are transferred is sharply different, due to fundamentally different working principles (electrochemical paradigms). In the case of $\mathbf{M v}$, the lack of reactivity of the one-electron-reduced intermediate is basically due to delocalization of this electron over the whole molecular skeleton whereas in the case of $\mathbf{2}$ and 3, it is rather related to the transient nature of the one-electron-reduced species due to potential inversion as well as its buried nature due to the inner location of pivotal SupLUMO/SupSOMO. This latter situation is due to inversion of electrochemical potentials and, to a lesser extent, the lowered spin density at $\alpha$ positions as a result of its withdrawal towards the $C(\gamma)$ sites, hence the uncompetitive intermolecular dimerization. Noteworthy, the inversion of potentials is demonstrated for both the filling of the SupLUMO reservoir (two-electron reduction with bond formation) and for the emptying of the filled reservoir taking the form of the SupHOMO (two-electron oxidation with bond breaking). 
Finally, super-electrophore $\mathbf{2}$ which, at first, can be regarded as the result of a rough design, turned out to be a relevant demonstrator and a proof of the "structronics" concept, in spite of its simplicity. This prototype has the great asset of cost-effectiveness thanks to its low engineering level as well as chemical robustness (see Sections 3.4 .1 and S27). These features both pertain to the "Sustainocene" criteria.5,6b of course, there is still a long way to go to reach truly workable devices that could enter the marketplace. Indeed, it is now a matter of designing electroactive molecular-based materials with a high density of "structronic" elements so as to obtain workable storage devices from the standpoint of charge-density. This could possibly be obtained by grafting "structronic" assemblies at the surface of conductive electrodes (e.g. graphene) or by embedding these functional elements within a matrix of conducting polymers or inside nanoporous conductive covalent organic frameworks (COFs), using electricity of photovoltaic origin. Actually, possible utilizations of superelectrophores span from the field of solution organic molecular chemistry (e.g. as new generation super-electrondonors, SED, ${ }^{71}$ which are adjustable and electrochemically rechargeable to deliver couples of redox equivalents) to the field of electrochemical energy storage devices, thus functioning as building blocks of organic ${ }^{72}$ or redox-flow ${ }^{73}$ batteries. From the standpoint of homogeneous artificial photosynthesis and, above all, of advanced Photochemical

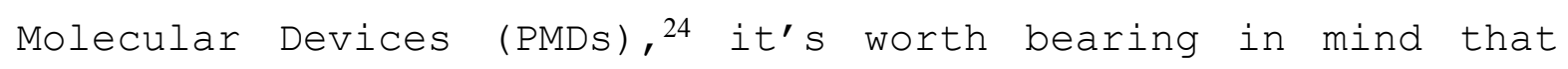
what can be done electrochemically can be achieved photochemically, provided that suitable photosensitizers are involved. Thus, the "structronic" (+ photosensitizers) functional component(s) can be associated with various catalysts (whether molecular or nanoparticulate) and with electron donors ${ }^{74}$ (whether sacrificial or not) to give 
molecular-level principles able to manage multi-photon/multielectron i.e. photosynthetic transduction processes.

\section{ASSOCIATED CONTENT}

Supporting Information (SI): Experimental Section; Complete ref. 12; X-ray structures of $\mathbf{1}\left[\mathrm{PF}_{6}\right], \quad \mathbf{2}\left[\mathrm{PF}_{6}\right]_{2}$ and $\mathbf{3}\left[\mathrm{PF}_{6}\right]_{2}$ along with cif files; optimized geometries and electronic structures of $\mathbf{1}, \mathbf{2} \& \mathbf{3}$ in their various redox states; ${ }^{13} \mathrm{C}$ solution $\mathrm{NMR}\left(\mathrm{CD}_{3} \mathrm{CN}\right)$ of $\mathbf{2}$ after chemical reduction; supplementary electrochemical studies of $\mathbf{2}$ and $\mathbf{3}$; complementary UV-Vis-NIR and FTIR SEC experimental data along with corresponding calculated data; further considerations regarding electrochemical hysteresis of other known organic redox systems with electrochemically triggered bond formation/cleavage (DyRex systems); syntheses and full characterization of the various compounds. The supporting Information is available free of charge on the ACS Publications website.

\section{AUTHOR INFORMATION}

\section{Corresponding authors}

hyacinthe.randria@univ-paris-diderot.fr;

Ilaria.ciofini@chimie-paristech.fr; magdalena.hromadova@jh-inst.cas.cz;

lubomir.pospisil@jh-inst.cas.cz

philippe.laine@univ-paris-diderot.fr

\section{ORCID}

Romana Sokolová: 0000-0003-1705-7401

Magdaléna Hromadová, : 0000-0002-3138-6917

Ilaria Ciofini: 0000-0002-5391-4522

Lubomír Pospíšil: 0000-0003-2543-2195

Henri-Pierre Jacquot de Rouville: 0000-0002-9508-6446

Hyacinthe Randriamahazaka: 0000-0002-8256-7486

Grégory Dupeyre: 0000-0002-4528-2481

Philippe P. Lainé: 0000-0001-7053-1833 


\section{Conflicts of interest.}

The authors declare no competing financial interest.

\section{Acknowledgment}

Financial supports by the Grant Agency of the Czech Republic (18-04682S), and the Academy of Sciences of the Czech Republic (RVO: 61388955, 61388963), the Ministry of Education of the Czech Republic (Barrande project 7AMB15FR027), the French Ministries of Europe and Foreign Affairs (MAE) and of Advanced Education, Research and Innovation (MESRI) (PHC Barrande, 2015 project $\mathrm{N}^{\circ}$ 34012SC), the European Research Council (ERC) under the European Union's Horizon 2020 research and innovation program (grant agreement No 648558) and the French National Research Agency, ANR ("E-StorIc" project : ANR-14-CE05-0002), are gratefully acknowledged.

\section{Notes and references}

1 (a) Lorius, C.; Jouzel, J.; Ritz, C.; Merlivat, L.; Barkov, N. I.; Korotkevich Y. S.; Kotlyakov, V. M. A 150,000-year climatic record from Antarctic ice. Nature, 1985, 316, 591-596; (b) Barnola, J. M.; Raynaud, D.; Korotkevich, Y. S.; Lorius, C. Vostok ice core provides 160,000-year record of atmospheric $\mathrm{CO}_{2}$. Nature, 1987, 329, 408-414; (c) Lorius, C.; Jouzel, J.; Raynaud, D.; Hansen, J.; Le Treut, H. The ice-core record: climate sensitivity and future greenhouse warming. Nature, 1990, 347, 139-145.

2 Crutzen, P. J. Geology of mankind. Nature, 2002, 415, 23.

3 (a) Service, R. F. Is It Time to Shoot for the Sun? Science, 2005, 309, 548-551; (b) Crabtree G. W.; Lewis, N. S. Solar energy conversion. Physics Today, 2007, 60, 37-42; (c) Lewis, N. S. Toward Cost-Effective Solar Energy Use. Science, 2007, 315, 798-801.

4 (a) Kerr R. A.; Service, R. F. What Can Replace Cheap Oil-and When? Science, 2005, 309, 101; (b) Lewis N. S.; Nocera, D. G. Powering the planet: Chemical challenges in solar energy utilization. Proc. Natl. Acad. Sci. U.S.A., 2006, 103, 15729-15735; (c) Armaroli N.; Balzani, V. The Future of Energy Supply: Challenges and Opportunities. Angew. Chem., Int. Ed. Engl., 2007, 46, 52-66; (d) Pellegrin Y.; Odobel, F. Molecular devices featuring sequential photoinduced charge separations for the storage of multiple redox equivalents. Coord. Chem. Rev. 2011, 255, 2578-2593.

5 Faunce, T. Towards a global solar fuels project-Artificial photosynthesis and the transition from anthropocene to sustainocene. Procedia Eng., 2012, 49, 348-356.

6 (a) Reece, S. Y.; Hamel, J. A.; Sung, K.; Jarvi, T. D.; Esswein, A. J.; Pijpers, J. J. H.; Nocera, D. G. Wireless Solar Water Splitting Using Silicon-Based Semiconductors and Earth-Abundant Catalysts. Science, 2011, 334, 645-648; (b) Nocera, D. G. Chemistry of Personalized Solar Energy. Inorg. Chem., 2009, 48, 10001-10017.

7 (a) Rutherford W. A.; Moore, T. A. Mimicking photosynthesis, but just the best bits. Nature, 2008, 453, 449; (b) Balzani, V.; Credi A.; Venturi, M. Photochemical Conversion of Solar Energy. Chem. Sus. Chem., 2008, 1, 26-58; (c) Benniston, A. C.; Harriman, A. Artificial photosynthesis. Mater. Today, 2008, 11, 26-34; (d) Gray, H. B. Powering the planet with solar fuel. Nature Chem., 2009, 1, 7; (e) 
Magnuson, A.; Anderlund, M.; Johansson, O.; Lindblad, P.; Lomoth, R.; Polivka, T.; Ott, S.; Stensjö, K.; Styring, S.; Sundström V.; Hammarström, L. Biomimetic and Microbial Approaches to Solar Fuel Generation. AcC. Chem. Res., 2009, 42, 1899-1909; (f) Nocera, D. G. The Artificial Leaf. Acc. Chem. Res., 2012, 45, 767-776; (g) Wasielewski, M. R. Energy, Charge, and Spin Transport in Molecules and Self-Assembled Nanostructures Inspired by Photosynthesis. J. Org. Chem., 2006, 71, 5051-5066; (h) Bard A. J.; Fox, M. A. Artificial Photosynthesis: Solar splitting of water to Hydrogen and Oxygen. ACC. Chem. Res., 1995, 28, 141-145; (i) M. Grätzel, Photoelectrochemical cells. Nature, 2001, 414, 338-344; (j) Hambourger, M.; Moore, G. F.; Kramer, D. M.; Gust, D.; Moore A. L.; Moore, T. A. Biology and technology for photochemical fuel production. Chem. Soc. Rev., 2009, 38, 25-35; (k) Alstrum-Acevedo, J. H.; Brennaman M. K.; Meyer, T. J. Chemical Approaches to Artificial Photosynthesis. 2. Inorg. Chem., 2005, 44, 6802-6827; (1) Knör, G. Recent progress in homogeneous multielectron transfer photocatalysis and artificial photosynthetic solar energy conversion. Coord. Chem. Rev., 2015, 304-305, 102-108.

8 O'Regan, B.; Grätzel, M. A low-cost, high-efficiency solar cell based on dye-sensitized colloidal $\mathrm{TiO}_{2}$ film. Nature, 1991, 353, 737740 .

9 (a) Boulas, P. L.; Gomez-Kaifer M.; Echegoyen, L. Electrochemistry of Supramolecular Systems. Angew. Chem. Int. Ed., 1998, 37, 216-247; (b) Xie, Q.; Pérez-Cordero E.; Echegoyen, L. Electrochemical Detection of $\mathrm{C}_{60}{ }^{6-}$ and $\mathrm{C}_{70^{6-}}$ : Enhanced Stability of Fullerides in Solution. J. Am. Chem. Soc., 1992, 114, 3978-3980. (c) Ruben, M.; Breuning, E.; Gisselbrecht J.-P.; Lehn, J.-M. Multilevel molecular electronic species: Electrochemical reduction of a $\left[\begin{array}{llll}2 & \mathrm{x} & 2\end{array}\right]$ Co(II) 4 grid-type complex by 11 electrons in 10 reversible steps. Angew. Chem. Int. Ed., 2000, 39, 4139-4142.

10 (a) Astruc, D. Ferrocenyl dendrimers: multi-electron redox reagents and their applications. New J. Chem., 2011, 35, 764-772 and references therein; (b) Ronconi, C. M.; Stoddart, J. F.; Balzani, V.; Baroncini, M.; Ceroni, P.; Giansante C.; Venturi, M. Polyviologen Dendrimers as Hosts and Charge-Storing Devices. Chem.Eur. J., 2008, 14, 8365-8373; (c) Mayor, M.; Lehn, J.-M. Reducible Nanosize Macrocycles. J. Am. Chem. Soc. 1999, 121, 11231-11232.

11 For an example of a one-photon gated reversible C-C bond, see: Waidhas, F.; Jevric, M.; Fromm, L.; Bertram, M.; Görling, A.; MothPoulsen, K.; Brummel, O.; Libuda, J. Electrochemically controlled energy storage in a norbornadiene-based solar fuel with 99\% reversibility. Nano Energy 2019, 63, 103872 and references therein.

12 Adams, D. M. et al. Charge Transfer on the Nanoscale: Current Status. J. Phys. Chem. B, 2003, 107, 6668-6697 and references therein.

13 (a) Kertesz, M. Pancake Bonding: An Unusual Pi-Stacking Interaction. Chem. - Eur. J., 2019, 25, 400-416; (b) Mou Z.; Kertesz, M. Sigmaversus Pi-Dimerization Modes of Triangulene. Chem. - Eur. J., 2018, $24,6140-6147$.

14 Fortage, J.; Peltier, C.; Nastasi, F.; Puntoriero, F.; Tuyèras, F.; Griveau, S.; Bedioui, F.; Adamo, C.; Ciofini, I.; Campagna S.; Lainé, P. P. Designing Multifunctional Expanded Pyridiniums: Properties of Branched and Fused Head-to-Tail Bipyridiniums. J. Am. Chem. Soc., 2010, 132, 16700-16713.

15 Marder, S. R.; Cheng, L.-T.; Tiemann, B. G.; Friedli, A. C.; Blanchard-Desce, M.; Perry J. W.; Skindhej, J. Large First Hyperpolarizabilities in Push-Pull Polyenes by Tuning of the Bond 
Length Alternation and Aromaticity. Science, 1994, 263, 511-514. (a) Fortage, J.; Peltier, C.; Perruchot, C.; Takemoto, Y.; Teki, Y. Bedioui, F.; Marvaud, V.; Dupeyre, G.; Pospíšil, L.; Adamo, C.; Hromadová, M.; Ciofini I.; Lainé, P. P. Single-Step versus Stepwise Two-Electron Reduction of Polyarylpyridiniums: Insights from the Steric Switching of Redox Potential Compression. J. Am. Chem. Soc., 2012, 134, 2691-2705; (b) Lachmanová, Š.; Dupeyre, G.; Tarábek, J.; Ochsenbein, P.; Perruchot, C.; Ciofini, I.; Hromadová, M.; Pospíšil L.; Lainé, P. P. Kinetics of Multielectron Transfers and RedoxInduced Structural Changes in N-Aryl-Expanded Pyridiniums: Establishing Their Unusual, Versatile Electrophoric Activity. J. Am. Chem. Soc., 2015, 137, 11349-11364.

17 Pascal Jr., R. A. Twisted Acenes. Chem. Rev., 2006, 106, 4809-4819.

18 Cross, W.; Hawkes, G. E.; Kroemer, R. T.; Liedl, K. R.; Loerting, T.; Nasser, R.; Pritchard, R. G.; Steele, M.; Watkinson M.; Whiting, A. The structure, modelling and dynamics of hindered 5,6diarylacenaphthenes. J. Chem. Soc., Perkin Trans. 2, 2001, 459-467.

19 (a) Brown, H. C.; Bartholomay Jr. H.; Taylor. M. D. Acid-Base Studies in Gaseous Systems. 11. The Anomalous Base Strength of the Methylamines; A New Manifestation of Steric Strain. J. Am. Chem. Soc., 1944, 66, 435-442; (b) Hounshell, W. D.; Dougherty, D. A.; Hummel J. P.; Mislow, K. Structure of Hexaphenylethane and Congeners as Determined by Empirical Force Field Calculations. J. Am. Chem. Soc., 1977, 99, 1916-1924.

20 (a) Lima, C. F. R. A. C.; Rocha, M. A. A.; Gomes, L. R.; Low, J. N.; Silva, A. M. S.; Santos, L. M. N. B. F. Experimental support for the Role of Dispersion Forces in Aromatic Interactions. Chem.-Eur. J., 2012, 18, 8934-8943; (b) Pieters, G.; Terrasson, V.; Gaucher, A.; Prim D.; Marrot, J. Synthesis and Molecular Structure of Symmetrical 1,8-Diarylnaphthalenes. Eur. J. Org. Chem., 2010, 30, 5800-5806.

21 (a) Bondi, A. van der Waals Volumes and Radii. J. Phys. Chem., 1964, 68, 441-451; (b) Chebny, V. J.; Shukla R.; Rathore, R. Toroidal Hopping of a Single Hole through the Circularly-Arrayed Naphthyl Groups in Hexanaphthylbenzene Cation Radical. J. Phys. Chem. A, 2006, 110, 13003-13006.

22 It's worth noting that the potentially repelling cationic charges are not located at the short contact site where bond formation is expected, hence reducing accordingly electrostatic strain (demand) within the native assembly.

23 When using the reading grid of electrochemical reactivity in the potential range spanning from $-2 \mathrm{~V}$ to $+1 \mathrm{~V}$ (vs. SCE in acetonitrile), the sole pyridylium groups, that are spatially disjointed, are redox active. They are structurally gathered by the electrochemicallyinactive naphthalene scaffold, hence the notion of supramolecular assemblies used for these super-electrophores within the present context of electrochemistry. This reading grid is very similar to that perfected by V. Balzani24 for the field of Supramolecular Photochemistry, in the context of photochemistry.

24 (a) Balzani, V.; Moggi L.; Scandola F. in Supramolecular Photochemistry, (Eds.: V. Balzani, D. Reidel) Publishing Co., Dordrecht, The Netherlands, 1987, pp. 1-28; (b) Balzani, V. Supramolecular Photochemistry. Tetrahedron, 1992, 48, 10443-10514.

25 As regards MVs, it is worth noting that close cofacial contact of these electrophores is likely to impact their electronic structure and reactivity. This phenomenon is observed whether these MVs are tightly tethered, in high concentration, organized in self-assembled monolayers or encapsulated in supramolecular host-guest assemblies. The result is the formation of $\pi$ complex dimers exhibiting redox behaviors distinguishable from that of isolated MV. For representative references, see (a) Burgess, M.; Chénard, E.; Hernández-Burgos, K.; Nagarjuna, G.; Assary, R. S.; Hui, J.; Moore, 
J. S.; Rodríguez-López, J. Impact of Backbone Tether Length and Structure on the Electrochemical Performance of Viologen Redox Active Polymers. Chem. Mater., 2016, 28, 7362-7374; (b) MacInnes, M. M.; Cousineau, B. R.; Youngs, S. M.; Sinniah, K.; Reczek, J. J.; Maldonado, S. Discovery of Unusually Stable Reduced Viologen via Synergistic Folding and Encapsulation. J. Electrochem. Soc., 2019, 166, H825-H834; (c) Tang, X.; Schneider, T. W.; Walker, J. W.; Buttry, D. A. Dimerized $\pi$-Complexes in Self-Assembled Monolayers Containing Viologens: An Origin of Unusual Wave Shapes in the Voltammetry of Monolayers. Langmuir, 1996, 12, 5921-5933.

. Takimiya, K.; Otsubo, T.; Aso, i Nakamura, T.; Araki Y.; Ito, O. Synthesis and Photophysical Properties of FerroceneOligothiophene-Fullerene Triads. J. Org. Chem., 2004, 69, 7183-7189. Fortage, J.; Tuyèras, F.; Ochsenbein, P.; Puntoriero, F.; Nastasi, F.; Campagna, S.; Griveau, S.; Bedioui, F.; Ciofini I.; Lainé, P. P. Expanded Pyridiniums: Bis-cyclization of Branched Pyridiniums into Their Fused Polycyclic and Positively Charged Derivatives-Assessing the Impact of Pericondensation on Structural, Electrochemical, Electronic, and Photophysical Features. Chem. - Eur. J., 2010, 16, 11047-11063.

28 Clough, R. L.; Kung, W. J.; Marsh R. E.; Roberts, J. D. Structural Analysis of Internally Crowded Naphthalene Derivatives. periDiphenylacenaphthene. J. Org. Chem., 1976, 41, 3603-3609.

29 Schmidt, H. C.; Spulber, M.; Neuburger, M.; Palivan, C. G.; Meuwly M.; Wenger, O. S. Charge Transfer Pathways in Three Isomers of Naphthalene-Bridged Organic Mixed Valence Compounds. J. Org. Chem., 2016, 81, 595-602; and references cited therein.

30 (a) Connelly N. G.; Geiger, W. E. Chemical Redox Agents for Organometallic Chemistry. Chem. Rev., 1996, 96, 877-910; (b) Balej, $\mathrm{J}$. Standard potential of sodium amalgam at $25^{\circ} \mathrm{C}$. Electrochim. Acta, 1976, 21, 953-956.

31 Noteworthy, calculated chemical shifts using DFT were in good agreement with the experiments and gives some insight on the nature of $\mathbf{2}^{0}$ (see Section S11 in SI). An important geometry change was calculated from the native form $2\left[\mathrm{PF}_{6}\right]_{2}$ to the reduced form $\mathbf{2}^{0}$ in agreement with the loss of aromaticity and the emergence of a quinoid form for the pyridinium subunits.

32 Evans, D. H. One-Electron and Two-Electron Transfers in Electrochemistry and Homogeneous Solution Reactions. Chem. Rev., 2008, 108, 2113-2144 and references therein.

33 There is no specific reference but one can take the instance of bond formation in dihydrogen molecule: Caruso, F.; Rohr, D. R.; Hellgren, M.; Ren, X.; Rinke, P.; Rubio A.; Scheffler, M. Bond Breaking and Bond Formation: How Electron Correlation is Captured in Many-Body Perturbation Theory and Density-Functional Theory. Phys. Rev. Lett., 2013, 110, 146403 .

34 For the Red-1 process of $2^{2+}$, the measurement of $\left|E_{\mathrm{p}}-E_{\mathrm{p} / 2}\right|$ (where $E_{\mathrm{p} / 2}$ is the half-peak potential) was found to be $38 \mathrm{mV}$, which agrees with a bi-electronic process for an irreversible system. ${ }^{35}$ As regards $1^{+}$, the $\left|E_{p}-E_{p / 2}\right|$ value of the Red-1 process amounts to $51.6 \mathrm{mV}$, as approximately expected for a reversible mono-electronic process. ${ }^{34}$

35 Bard, A. J.; Faulkner, L. R. Electrochemical Methods. Fundamentals and Applications, Second Ed., Chapter 6, Wiley, New York, 2001.

$36 E_{1 / 2}$ is calculated as $\left(E_{\mathrm{pa}}+E_{\mathrm{pc}}\right) / 2$, where $E_{\mathrm{pa}}$ and $E_{\mathrm{pc}}$ are the anodic and cathodic peak potentials.

37 Electrophoric concentrations used for electrochemical studies reported in ref. $16 \mathrm{a}$ were about $0.5 \mathrm{mM}$, like here, instead of $5 \mathrm{mM}$, as incorrectly indicated in the experimental section of this paper. Given that the current varies as the square root of the potential scan rate $\left(\mathrm{V}^{1 / 2}\right)$, direct comparison of CVs recorded at different scan 
rates $\left(0.1 \mathrm{~V} \mathrm{~s}^{-1}\right.$ and $\left.0.625 \mathrm{~V} \mathrm{~s}^{-1}\right)$ is therefore possible provided that actual current is normalized against $V^{1 / 2}$. This data treatment also justifies the choice of peculiar $V$ values (e.g. 25, 100, 225, 400 or $625 \mathrm{mV} \mathrm{s}^{-1}$ ) in electrochemical studies where the impact of the rate of applied voltage is investigated (e.g. Current $I$ (mA) as the function of $V^{1 / 2}\left(V\right.$ in $\left.\left.\mathrm{mV} \mathrm{s}^{-1}\right)\right)$, as it gives convenient incremental $V^{1 / 2}$ values (i.e. 5, 10, 15, 20 or $25 \mathrm{mV}^{1 / 2} \mathrm{~s}^{-1 / 2}$ ); see Figure $\mathrm{S} 17$ in SI.

39 By plotting $\left(I_{\text {red }} / V\right.$ ) versus $\left(V^{-1 / 2}\right)$ (see Figure S17 in section S25.2 of the SI), where $I_{\text {red }}$ is the cathodic peak current, a linear relationship is obtained for both mono- and di-pyridinium assemblies (1 and 2). This observation clearly demonstrates that (1) there is no adsorption of the electroactive species at the $\mathrm{Pt}$ electrode surface and (2) the current is controlled by a semi-infinite linear diffusion process.

40 Home-made codes were written for the convolution analysis using algorithm suggested by Oldham; see Oldham, K. B. Convolution: A General Electrochemical Procedure Implemented by a Universal Algorithm, Anal. Chem., 1986, 582, 2296-2300.

41 Teplý, F.; Čížková, M.; Slavíček, P.; Kolivoška, V.; Tarábek, J.; Hromadová M.; Pospíšil, L. Electron Transfer Triggers Fast Dimer/Monomer Switching of Pyridinium and Quinolinium Cations. $J$. Phys. Chem. C, 2012, 116, 3779-3786.

42 Hromadová, M.; Pospíšil, L.; Sokolová R.; Kolivoška, V. Electrochemical reduction of dodecylpyridinium bromide in aprotic solvents: mechanistic studies. Collect. Czech. Chem. Commun., 2011, 76, 1895-1908.

43 Brandt, J. R.; Pospíšil, L.; Bednárová, L.; Correa da Costa, R.; White, A. J. P.; Mori, T.; Teplý F.; Fuchter, M. J. Intense redoxdriven chiroptical switching with a $580 \mathrm{mV}$ hysteresis actuated through reversible dimerization of an azoniahelicene. Chem. Commun., 2017, 53, 9059-9062.

44 Plutnar, J.; Hromadová, M.; Ramešová, Š.; Havlas Z.; Pospíšil, L. Electron Transfer Mechanism of Substituted Benzimidazoles: Dimer Switching, Oscillations, and Search for Singlet Fission Properties. J. Phys. Chem. C., 2017, 121, 9963-9969.

45 Mairanovsky, S. G. The polarographic behavior of quaternary pyridinium salts. Dokl. Akad. Nauk SSSR, 1956, 110, 593-596.

46 (a) Michaelis, L.; Hill, E. S. The viologen indicators. J. Gen. Physiol., 1933, 16, 859-873; (b) Dimroth O.; Hoene, R. Reduction of pyridine with zinc dust and acetic acid anhydride. Ber. Dtsch. Chem. Ges., 1921, 54, 2934-2942.

47 Koutecký, J.; Hanuš, V. Zwei beispiele schneller, in den depolarisationvorgang an der tropfelektrode eingeschalteter, bimolekularer reaktionen. Collect. Czech. Chem. Commun., 1955, 20, 124-138.

48 Gaudiello, J. G.; Larkin, D.; Rawn, J. D.; Bancroft E. E.; Blount, H. N. On the mechanism of the electrochemical reduction of $N^{-}$ methylpyridinium ion. J. Electroanal. Chem., 1982, 131, 203-214.

49 Olmstead, M. L.; Hamilton R. G.; Nicholson, R. S. Theory of Cyclic Voltammetry for a Dimerization Reaction Initiated Electrochemically. Anal. Chem., 1969, 41, 260-267.

50 Andrieux, C. P.; Nadjo L.; Savéant, J.-M. Electrodimerization: I. One-electron irreversible dimerization. Diagnostic criteria and rate determination procedures for voltammetric studies. J. Electroanal. Chem., 1970, 26, 147-186.

51 (a) Imbeaux J. C.; Savéant, J.-M. Convolutive potential sweep voltammetry: I. Introduction. J. Electroanal. Chem., 1973, 44, 169187; (b) Ammar, F.; Savéant, J.-M. Convolutive potential sweep voltammetry: II. Multistep Nernstian waves. J. Electroanal. Chem., 1973, 47, 215-221. 
Hall, G. B.; Kottani, R.; Felton, G. A. N.; Yamamoto, T.; Evans, D. H.; Glass R. S.; Lichtenberger, D. L. Intramolecular Electron Transfer in Bipyridinium Disulfides. J. Am. Chem. Soc., 2014, 136, 4012-4018.

53 Suzuki, T.; Nishida J.-i.; Tsuji, T. A new type of tricolor electrochromic system based on the dynamic redox properties of hexaarylethane derivatives. Chem. Commun., 1998, 2193-2194.

Suzuki, T.; Takeda, T.; Kawai H.; Fujiwara, K. Ultralong C-C bonds in hexaphenylethane Derivatives. Pure Appl. Chem., 2008, 80, 547553.

Suzuki, T.; Takeda, T.; Ohta, E.; Wada, K.; Katoono, R.; Kawai H.; Fujiwara, K. Bis(10-methylacridinium)s as a Versatile Platform for Redox-Active Functionalized Dyes and Novel Structures. Chem. Rec., 2015, 15, 280-294.

56 Takeda, T.; Uchimura, Y.; Kawai, H.; Katoono, R.; Fujiwara K.; Suzuki, T. Hexaphenylethanes with an Ultralong CC Bond: Expandability of the CC Bond in Highly Strained Tetraarylpyracenes. Chem. Lett., 2013, 42, 954-962.

57 Bettinger, H. F.; Schleyer P. V. R.; Schaefer III, H. F. Tetraphenyldihydrocyclobutaarenes - what causes the extremely long $1.72 \AA \mathrm{A}-\mathrm{C}$ single bond?. Chem. Commun., 1998, 769-770.

58 Kammermeier, S.; Jones P. G.; Herges, R. [2 + 2] Cycloaddition Products of Tetradehydrodianthracene : Experimental and Theoretical Proof of Extraordinary Long C - C Single Bonds. Angew. Chem., Int. Ed. Engl., 1997, 36, 1757-1760.

59 Pauling, L. The Nature of the Chemical Bond and the Structure of Molecules and Crystals, 3rd ed.; Cornell University Press: Ithaca, NY, 1960; Chapters 7 and 8 .

60 Zavitsas, A. A. The Relation between Bond Lengths and Dissociation Energies of Carbon-Carbon Bonds. J. Phys. Chem. A, 2003, 107, 897898 .

61 Suzuki, T. Nishida J.-I.; Tsuji, T. Hexaphenylethane Derivatives Exhibiting Novel Electrochromic Behavior. Angew. Chem., Int. Ed. Engl., 1997, 36, 1329-1331.

62 (a) Horner M.; Hünig. S. Conjugation in Bicyclo[1.1.0]butanes. LUMO Properties of the Bridging Bond. J. Am. Chem. Soc., 1977, 99, 61226124; (b) Hünig, S.; Briehn, C. A.; Bäuerle P.; Emge, A. Electrochromics by Intramolecular Redox Switching of Single Bonds. Chem.-Eur. J., 2001, 7, 2745-2757.

63 For an example of electrochemically gated covalent sulfur-sulfur bond formation/cleavage, see refs 52 and Benniston, A. C.; Hagon, J.; He, X.; Yang S.; Harrington, R. W. Spring Open Two-plus-Two Electron Storage in a Disulfide-Strapped Methyl Viologen Derivative. Org. Lett., 2012, 14, 506-509.

64 (a) Suzuki, T.; Wada, K.; Ishigaki, Y.; Yoshimoto, Y.; Ohta, E.; Kawai H.; Fujiwara, K. Drastic change in racemization barrier upon redox reactions: novel chiral-memory units based on dynamic redox systems. Chem. Commun., 2010, 46, 4100-4102; (b) Suzuki, T.; Ishigaki, Y.; Iwai, T.; Kawai, H.; Fujiwara, K.; Ikeda, H.; Kano Y.; Mizuno, K. Multi-Input/Multi-Output Molecular Response System Based on the Dynamic Redox Behavior of 3,3,4,4 Tetraaryldihydro[5]helicene Derivatives: Reversible Formation/Destruction of Chiral Fluorophore and Modulation of Chiroptical Properties by Solvent Polarity. Chem. Eur. J., 2009, 15, 9434-9441; (c) Suzuki, T.; Sakano, Y.; Iwai, T.; Iwashita, S.; Miura, Y.; Katoono, R.; Kawai, H.; Fujiwara, K.; Tsuji Y.; Fukushima, T. 7,7,8,8-Tetraaryl-o-quinodimethane Stabilized by Dibenzo Annulation: A Helical $\pi$-Electron System That Exhibits Electrochromic and Unique Chiroptical Properties. Chem. -Eur. J., 2013, 19, 117-123.

65 (a) Ohta, E.; Nehira, T.; Kawai, H.; Fujiwara K.; Suzuki, T. Fourway-output molecular response system based on the 
dihydrodibenzo[c,g]phenanthrene skeleton: modulation of CD and FDCD activity by acid and electron-transfer. Tetrahedron Lett., 2008, 49, 777-781; (b) Nishida, J.-I.; Miyagawa T.; Yamashita, Y. Novel Thiophene Oligomers Containing a Redox Active Hexaarylethane Unit. Org. Lett., 2004, 6, 2523-2526.

66 Suzuki, T.; Tanaka, S.; Kawai H.; Fujiwara, K. Multi-input-Multioutput Molecular Response System Based on Dynamic Redox Behavior of Hexaphenylethane-type Electron with the Tetrahydrophenanthrazepine Skeleton: Strong Chiroptical Signals through the Transmission of Point Chirality to Helicity. Chem. Asian J. , 2007, 2, 171-177.

67 (a) Logtenberg H.; Browne, W. R. Electrochemistry of dithienylethenes and their application in electropolymer modified photo- and redox switchable surfaces. Org. Biomol. Chem., 2013, 11, 233-243; (b) Staykov, A.; Areephong, J.; Browne, W. R.; Feringa B. L.; Yoshizawa, K. Electrochemical and Photochemical Cyclization and Cycloreversion of Diarylethenes and Diarylethene-Capped Sexithiophene Wires. ACS Nano, 2011, 5, 1165-1178; (c) Gilat, S. L.; Kawai S. H.; Lehn, J.-M.Light-Triggered Molecular Devices: Photochemical Switching of Optical and Electrochemical Properties in Molecular Wire Type Diarylethene Species. Chem. -Eur. J., 1995, 1, 275-284; (d) Peters A.; Branda, N. R. Electrochemically induced ring-closing of photochromic 1,2-dithienylcyclopentenes. Chem. Commun., 2003, 954-955; (e) Gorodetsky, B.; Samachetty, H. D.; Donkers, R. L.; Workentin M. S.; Branda, N. R. Reductive Electrochemical Cyclization of a Photochromic 1,2Dithienylcyclopentene Dication. Angew. Chem., Int. Ed. Engl., 2004, 43, 2812-2815; (f) Moriyama, Y.; Matsuda, K.; Tanifuji, N.; Irie S.; Irie, Electrochemical Cyclization/Cycloreversion Reactions of Diarylethenes. Org. Lett., 2005, 7, 3315-3318.

68 Rathore, R.; Le Magueres, P.; Lindeman S. V.; Kochi, J. K. A RedoxControlled Molecular Switch Based on the Reversible C-C Bond Formation in Octamethoxytetraphenylene. Angew. Chem. Int. Ed. 2000, $39,809-812$.

69 (a) Kawai, H.; Takeda, T.; Fujiwara, K.; Wakeshima, M.; Hinatsu Y.; Suzuki, T. Ultralong Carbon-Carbon Bonds in Dispirobis(10methylacridan) Derivatives with an Acenaphthene, Pyracene, or Dihydropyracylene Skeleton. Chem. Eur. J., 2008, 14, 5780-5793; (b) Suzuki, T.; Yoshimoto, Y.; Takeda, T.; Kawai H.; Fujiwara, K. Intramolecular Methylacridan-Methylacridinium Complexes with a Phenanthrene-4,5-diyl or Related Skeleton: Geometry-Property Relationships in Isolable C-H Bridged Carbocations. Chem. - Eur. J., 2009, 15, 2210-2216; (c) Wada, K.; Takeda, T.; Kawai, H.; Katoono, R.; Fujiwara K.; Suzuki, T. Geometrical Remote Steric Effects in 4,5-Disubstituted-9,10-dihydrophenanthrenes: Expansion of Prestrained $\mathrm{C}^{9}-\mathrm{C}^{10}$ Bond in Di(spiroacridan) Derivatives. Chem. Lett., 2013, 42, 1194-1196; (d) Suzuki, T.; Migita, A.; Higuchi, H.; Kawai, H.; Fujiwara K.; Tsuji, T. A novel redox switch for fluorescence: drastic UV-vis and fluorescence spectral changes upon electrolysis of a hexaphenylethane derivative of 10,10'-dimethylbiacridan. Tetrahedron Lett., 2003, 44, 6837-6840; (e) Kawai, H.; Takeda, T.; Fujiwara K.; Suzuki, T. Short nonbond and long $\mathrm{C}-\mathrm{C}$ bond in naphthalene-1,8-diylbis(10-methylacridinium) and the corresponding hexaphenylethane derivative: a new electrochromic pair exhibiting dynamic redox properties. Tetrahedron Lett., 2004, 45, 8289-8293; (f) Suzuki, T.; Ohta, K.; Nehira, T.; Higuchi, H.; Ohta, E.; Kawai H.; Fujiwara, K. Unprecedented four-way-output molecular response system based on biphenyl-2,20-diyldiacridiniums: induction of axial chirality through intramolecular hydrogen bonds between chiral amide groups. Tetrahedron Lett., 2008, 49, 772-776. 
Luisi, P. L. Emergence in Chemistry: Chemistry as the Embodiment of Emergence. Foundat. Chem., 2002, 4, 183-200.

71 Of note, there exists a category of organic molecules denoted "Super Electron Donors", SED, that stores couples of electrons in chemical bonds and can serve as powerful reducers ("organic sodium"). Their limitation stems in the fact that they can be used only once (discharging); see for instance refs. (a) Murphy, J. A. Discovery and Development of Organic Super-Electron-Donors. J. Org. Chem. 2014, 79, 3731-3746; (b) Doni E.; Murphy, J. A. Evolution of neutral organic super-electron donors and their applications. Chem. Commun., 2014, 50, 6073-6087; (c) Zhou, S.; Anderson, G. M.; Mondal, B.; Doni, E.; Ironmonger, V.; Kranz, M.; Tuttle T.; Murphy, J. A. Organic super-electron-donors: initiators in transition metal-free haloarene-arene coupling. Chem. SCi., 2014, 5, 476-482.

Muench, S.; Wild, A.; Friebe, C.; Häupler, B.; Janoschka T.; Schubert, U. S. Polymer-Based Organic Batteries. Chem. Rev., 2016, $116,9438-9484$.

73 Antoni, P. W.; Bruckhoff T.; Hansmann, M. M. Organic Redox Systems Based on Pyridinium-Carbene Hybrids. J. Am. Chem. Soc., 2019, 141, 9701-9711.

74 Nomrowski J.; Wenger, O. S. Exploiting Potential Inversion for Photoinduced Multielectron Transfer and Accumulation of Redox Equivalents in a Molecular Heptad. J. Am. Chem. Soc., 2018, 140, 5343-5346.

\section{TOC Graphic}

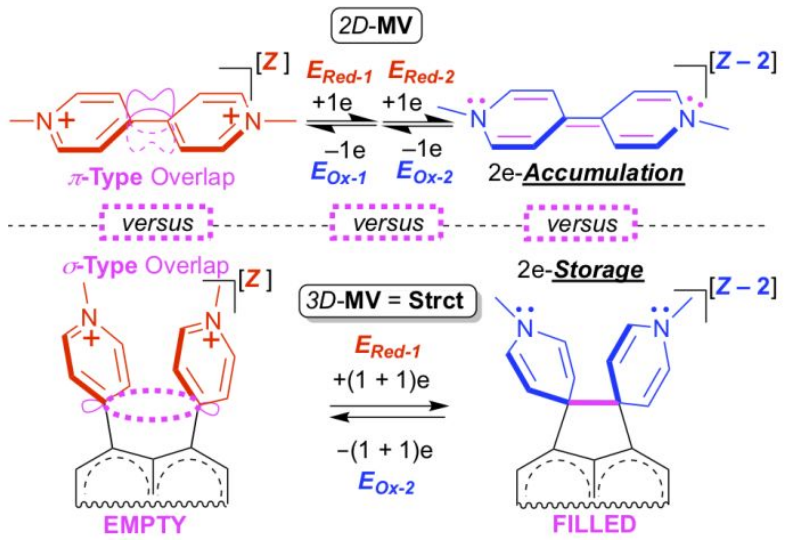

